\title{
Novel Gas Sensors for High-Temperature Fossil Fuel Applications
}

\section{Phase I Final Report}

Reporting Period: 1 October 2003 to 31 March 2005

\author{
Prepared by: \\ Dr. Palitha Jayaweera and Dr. Francis Tanzella \\ Materials Research Laboratory \\ SRI International \\ 333 Ravenswood Avenue \\ Menlo Park, CA 94025
}

March 2005

Prepared for:

U.S. Department of Energy

Award Number: DE-FC26-03NT41921 


\section{DISCLAIMER}

This report was prepared as an account of work sponsored by an agency of the United States Government. Neither the United States Government nor any agency thereof, nor any of their employees, makes any warranty, express or implied, or assumes any legal liability or responsibility for the accuracy, completeness, or usefulness of any information, apparatus, product or process disclosed, or represents that its use would not infringe privately owned rights. Reference herein to any specific commercial product, process, or service by trade name, trademark, manufacturer, or otherwise does not necessarily constitute or imply its endorsement, recommendation, or favoring by the United States Government or any agency thereof. The views and opinions of authors express herein do not necessarily state or reflect those of the United States Government or any agency thereof. 


\begin{abstract}
SRI International (SRI) is developing ceramic-based microsensors to detect exhaust gases such as $\mathrm{NO}, \mathrm{NO}_{2}$, and $\mathrm{CO}$ in advanced combustion and gasification systems under this DOE NETL-sponsored research project. The sensors detect the electrochemical activity of the exhaust gas species on catalytic electrodes attached to a solid state electrolyte and are designed to operate at the high temperatures, elevated pressures, and corrosive environments typical of large power generation exhausts. The sensors can be easily integrated into online monitoring systems for active emission control. The ultimate objective is to develop sensors for multiple gas detection in a single package, along with data acquisition and control software and hardware, so that the information can be used for closed-loop control in novel advanced power generation systems.

This report details the Phase I Proof-of-Concept, research activities performed from October 2003 to March 2005. SRI's research work includes synthesis of catalytic materials, sensor design and fabrication, software development, and demonstration of pulse voltammetric analysis of $\mathrm{NO}, \mathrm{NO}_{2}$, and $\mathrm{CO}$ gases on catalytic electrodes.
\end{abstract}




\section{CONTENTS}

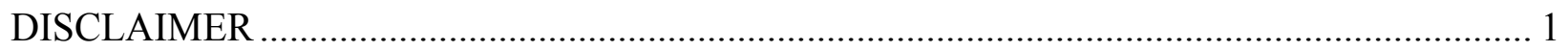

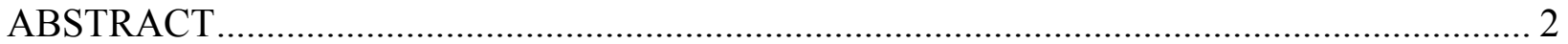

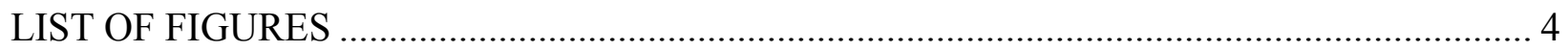

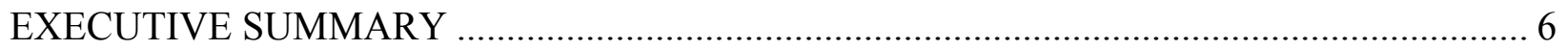

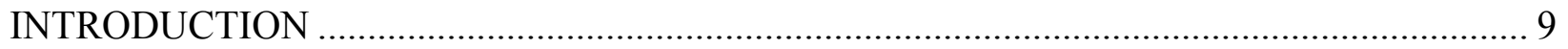

Purpose of the Project and Project Objectives..................................................................... 9

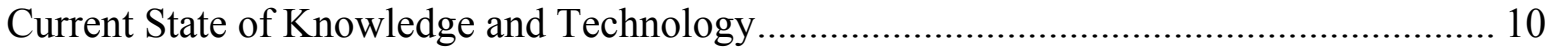

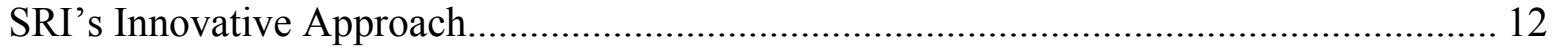

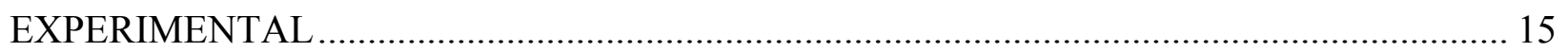

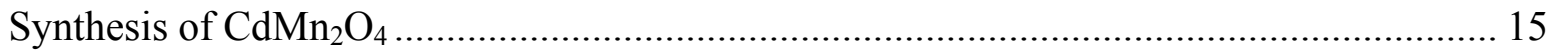

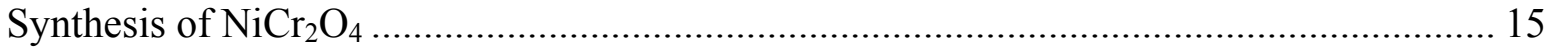

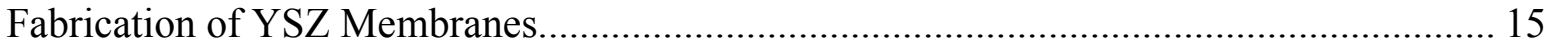

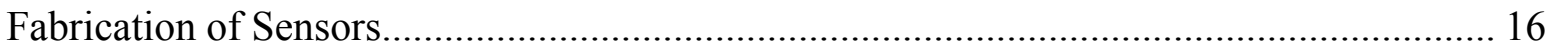

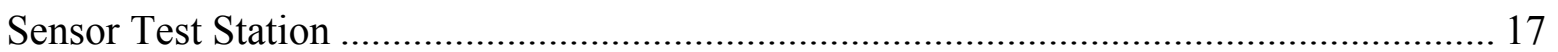

Computer Program Development ..................................................................................... 18

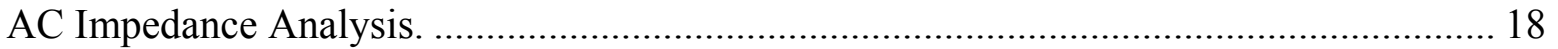

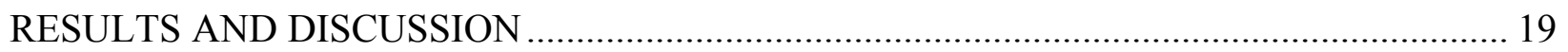

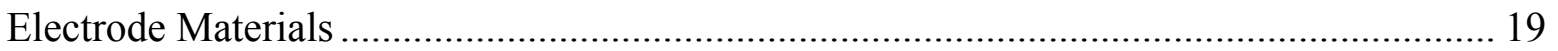

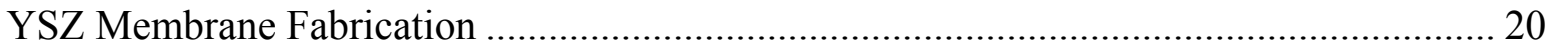

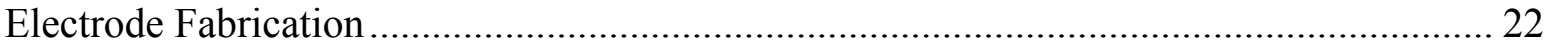

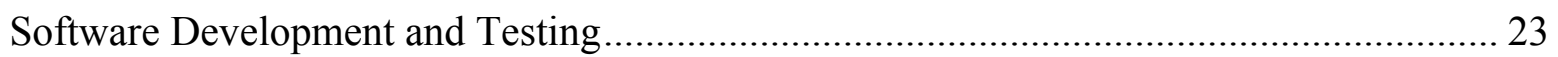

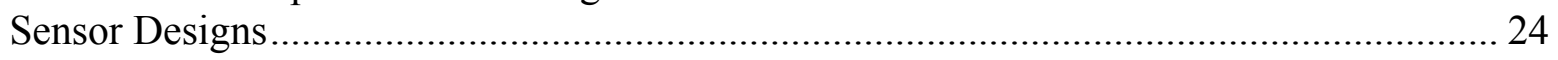

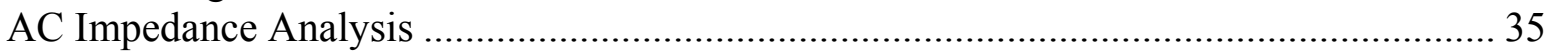

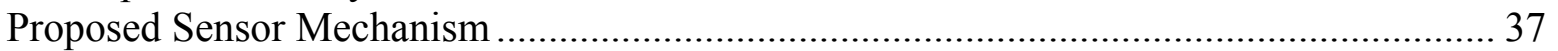

Temperature and Oxygen Concentration Limits............................................................ 37

Other Combustion Gas Monitoring Technologies ................................................................ 38

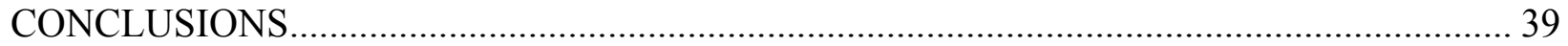

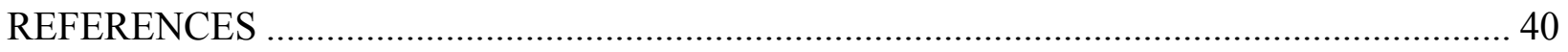




\section{LIST OF FIGURES}

Figure 1. Conceptual design of a sensor array for simultaneous multicomponent gas analysis . . 13

Figure 2. A typical differential pulse voltammetry waveform (a) and sensor response (b) . . . . . 14

Figure 3. Photographs of single sensor, Pt counter, reference electrodes, catalytic working electrode . . . 16

Figure 4. Photographs of a multielectrode design; Pt counter electrodes and the reference electrode in the center, and catalytic electrodes. Catalytic electrodes: 1- $\mathrm{NiCr}_{2} \mathrm{O}_{4}, 2-\mathrm{LSF}, 3-\mathrm{Pt}$, and $4-\mathrm{CdMn}_{2} \mathrm{O}_{4}$. . . . . . . . . . . . . . . . . . . . . . . . . . . . . . . . . . 17

Figure 5. Photographs of the sensor housing assembly and sensor element end . . . . . . . . . 17

Figure 6. Experimental setup for testing sensors . . . . . . . . . . . . . . . . . . . . . 18

Figure 7. $\mathrm{XRD}$ spectrum of $\mathrm{CdMn}_{2} \mathrm{O}_{4}$. . . . . . . . . . . . . . . . . . . . . . . . . . . . . . . 19

Figure 8. $\mathrm{XRD}$ spectrum of $\mathrm{NiCr}_{2} \mathrm{O}_{4}$. . . . . . . . . . . . . . . . . . . . . . . . . . . 20

Figure 9. DSC trace of the vaporization of $\mathrm{PPG}, \mathrm{BBP}$ and $\mathrm{PVB}$ during heating $\left(3^{\circ} \mathrm{C} / \mathrm{min}\right) \quad$. . . . . 21

Figure 10. TGA profile of plasticizer, release agent and binder during heating $\left(3^{\circ} \mathrm{C} / \mathrm{min}\right)$. . . . . 22

Figure 11. Graphical user interface window of the control program . . . . . . . . . . . . . . 23

Figure 12. Data output window of the program . . . . . . . . . . . . . . . . . . . . . . 24

Figure 13. Square wave voltammogram for $10^{-3} \mathrm{M} \mathrm{Cd}^{2+}$ and $\mathrm{Pb}^{2+}$ solution . . . . . . . . . . . . . . . 24

Figure 14. Two sensor designs $(\mathrm{A} 1$ and A2) . . . . . . . . . . . . . . . . . . . . . . . . . . . 25

Figure 15. Square wave voltammogram for $\mathrm{NO}$ at $700^{\circ} \mathrm{C}$ on $\mathrm{NiCr}_{2} \mathrm{O}_{4}$ electrodes . . . . . . . . . . . 26

Figure 16. Square wave voltammogram for $\mathrm{NO}_{2}$ at $700^{\circ} \mathrm{C}$ on $\mathrm{NiCr}_{2} \mathrm{O}_{4}$ electrodes . . . . . . . . . 27

Figure 17. Sensor design (B) with a Pt/air reference electrode. The catalytic electrode and the counter electrode are in the emission gas stream . . . . . . . . . . . . . . . . . . . . . 28

Figure 18. Sensor design (C) with a Pt/air reference electrode. The catalytic electrode is in the emission gas stream. Counter electrode and reference electrode are in the air-side . . . . . 28

Figure 19. $\mathrm{CdMn}_{2} \mathrm{O}_{4}$ sensor response to $\mathrm{NO}$ in $2 \% \mathrm{O}_{2}$ at $700^{\circ} \mathrm{C}$. . . . . . . . . . . . . . . . . . . . . . 29

Figure 20. Sensor design (D) with a Pt/air reference electrode. The catalytic electrode is underneath a porous YSZ membrane in the emission gas chamber. The counter and the reference electrodes are in the air side . . . . . . . . . . . . . . . . . . . . . . . . . . . . . . 30

Figure 21. $\mathrm{NiCr}_{2} \mathrm{O}_{4}$ sensor (D) response to $\mathrm{NO}$ in $2 \% \mathrm{O}_{2}$ at $700^{\circ} \mathrm{C}$. . . . . . . . . . . . . . . . . . . 30

Figure 22. Sensor design (E) with a Pt/air reference electrode. The catalytic electrode is underneath a porous-dense YSZ membrane in the emission gas chamber. The counter and the reference electrodes are in the air side . . . . . . . . . . . . . . . . . . . . . . . . . 31

Figure 23. Response of sensor design $\mathrm{E}$ with $\mathrm{CdMn}_{2} \mathrm{O}_{4}$ to $\mathrm{NO}_{2}$ in $5 \% \mathrm{O}_{2}$ at $500^{\circ} \mathrm{C}$. . . . . . . . 31

Figure 24. Calibration plot of sensor $\mathrm{E}$ with $\mathrm{CdMn}_{2} \mathrm{O}_{4}$ for $\mathrm{NO}_{2}$ in $5 \% \mathrm{O}_{2}$ at $500^{\circ} \mathrm{C}$. . . . . . . . 32

Figure 25. Response of sensor design $\mathrm{E}$ with $\mathrm{CdMn}_{2} \mathrm{O}_{4}$ to $\mathrm{NO}_{2}$ in $2 \% \mathrm{O}_{2}$ at $700^{\circ} \mathrm{C}$. . . . . . . . . 33

Figure 26. Calibration plot of sensor design $\mathrm{E}$ with $\mathrm{CdMn}_{2} \mathrm{O}_{4}$ for $\mathrm{NO}_{2}$ in $2 \% \mathrm{O}_{2}$ at $700^{\circ} \mathrm{C}$. . . . . 33 
Figure 27. Response of sensor design $\mathrm{E}$ with an $\mathrm{LSF}$ electrode to $\mathrm{NO}$ and $\mathrm{CO}$ in $2 \% \mathrm{O}_{2}$ at $700^{\circ} \mathrm{C}$. . . 34

Figure 28. Calibration plot of sensor design $\mathrm{E}$ with $\mathrm{LSF}$ electrode for $\mathrm{NO}$ and $\mathrm{CO}$ in $2 \% \mathrm{O}_{2}$ at $700^{\circ} \mathrm{C}$. . . 34

Figure 29. Nyquist plots for sensor design $\mathrm{E}$ with $\mathrm{CdMn}_{2} \mathrm{O}_{4}$ in $2 \% \mathrm{O}_{2}$ at $600^{\circ} \mathrm{C}$ with and without $100 \mathrm{ppm}^{2}$. . . . . . . . . . . . . . . . . . . . . . . . . . 35

Figure 30. Bode plots (impedance-frequency) for sensor design $\mathrm{E}$ with $\mathrm{CdMn}_{2} \mathrm{O}_{4}$ in $2 \% \mathrm{O}_{2}$ at $600^{\circ} \mathrm{C}$ with and without $100 \mathrm{ppm} \mathrm{NO}_{2}$. . . . . . . . . . . . . . . . . . . . 36

Figure 31. Bode plots (phase-frequency) for sensor design $\mathrm{E}$ with $\mathrm{CdMn}_{2} \mathrm{O}_{4}$ in $2 \% \mathrm{O}_{2}$ at $600^{\circ} \mathrm{C}$ with and without $100 \mathrm{ppm} \mathrm{NO}_{2}$. . . . . . . . . . . . . . . . . . . . . . . . 36 


\section{EXECUTIVE SUMMARY}

To address the critical need for on-line emission monitoring in advanced fossil fuel energy production systems, SRI International (SRI) is developing an array of miniature solidstate electrochemical sensors that are reliable, rugged, and inexpensive. We are conducting this sensor research program in two phases: Phase I includes the proof of concept and preliminary demonstration of a sensor package with multiple elements. Phase II involves in-depth analysis and testing of sensor arrays for stability, sensitivity, and selectivity; prototype development and testing; and identification of pathways for use in integrated sensor systems in fossil fuel energy conversion systems. The research activities discussed in this report were performed as part of the Phase I effort.

The high-temperature gas sensors being developed in this research program are based on solid-state ionic conducting and catalytic materials and could be used for on-line, real-time detection of $\mathrm{O}_{2}, \mathrm{NO}_{\mathrm{x}}, \mathrm{SO}_{\mathrm{x}}$, hydrocarbons (HC), and $\mathrm{CO}$ in exhaust gases. The sensors measure potential (potentiometric) and/or current (amperometric and voltammetric) in a solid-state electrochemical cell. The sensor array consists of a number of electrochemical cells fabricated with yttria-stabilized zirconia (YSZ) solid-state electrolyte and catalytic working electrodes. Each working electrode material is designed to be selective to a specific gas in the gas mixture. Selective detection of gases is enhanced by applying fast-pulse voltammetric techniques to the specific catalytic electrode, which is optimized for the gas of interest. The configuration and geometry of the electrode are also critical for obtaining the best sensor response. Thus, SRI's Phase I research work included selection and synthesis of suitable catalytic materials for detection of $\mathrm{NO}, \mathrm{NO}_{2}$, and $\mathrm{CO}$; fabrication of $\mathrm{YSZ}$ ceramic membranes with controlled microstructure; preparation of catalytic electrodes; electrochemical cell design; software development for pulse voltammetry; and testing of sensors in a simulated exhaust environment.

We have successfully demonstrated that $\mathrm{NO}, \mathrm{NO}_{2}$, and $\mathrm{CO}$ can be detected in the presence of excess $\mathrm{O}_{2}$ in a solid-state electrochemical cell using pulse voltammetric techniques on a catalytic electrode. The voltammograms show high sensitivity and selectivity as shown in Figure E1, thus the sensors show tremendous potential in online emission monitoring applications. The specific research activities performed in Phase I follow.

- Drawing on literature findings and our experience, we selected $\mathrm{CdMn}_{2} \mathrm{O}_{4}$ and $\mathrm{NiCr}_{2} \mathrm{O}_{4}$ as candidates for $\mathrm{NO}$ and $\mathrm{NO}_{2}$ detection, and $\mathrm{LaSrFeO}_{3}$ (LSF) for $\mathrm{CO}$ and $\mathrm{NO}$ detection. These catalytic materials were prepared by solid-state synthetic routes, and their phase structures were confirmed by X-ray diffraction.

- Paintable slurries of catalytic electrode materials were prepared with nanoparticles of the synthesized materials. The sensor electrodes were fabricated by painting the solid YSZ electrolyte with slurries made of appropriate materials and sintering at $750^{\circ} \mathrm{C}$. The adhesion of the catalytic electrode to the solid electrolyte was improved by optimizing the sintering program and the slurry composition. The counter and reference electrodes were prepared by painting with commercial Pt ink, followed by sintering.

- YSZ solid-state electrolyte was prepared by tape casting. The required cell geometries were cut with a laser from the "green" tape and sintered at $1400^{\circ} \mathrm{C}$ to obtain solid-state 
electrolyte membranes. For novel cell designs, solid/porous YSZ membranes were prepared by laminating "green" tapes with and without pore formers, followed by sintering.

- To run the pulse voltammetry scans on sensors, we developed software using Microsoft Visual Basic ${ }^{\circledR}$. We interfaced a potentiostat (EG\&G PAR 283) with a computer for data acquisition and experiment control. Software operation was verified with known electrochemical systems. The software is highly versatile and easily upgradeable to control the prototype sensor designs.

- We designed and fabricated a number of sensors with different electrode configurations. We tested these sensor designs with emission gas species to determine their sensitivity and selectivity in the presence of 1 to $5 \%$ oxygen. The tests were performed at temperatures from $500^{\circ}$ to $900^{\circ} \mathrm{C}$.

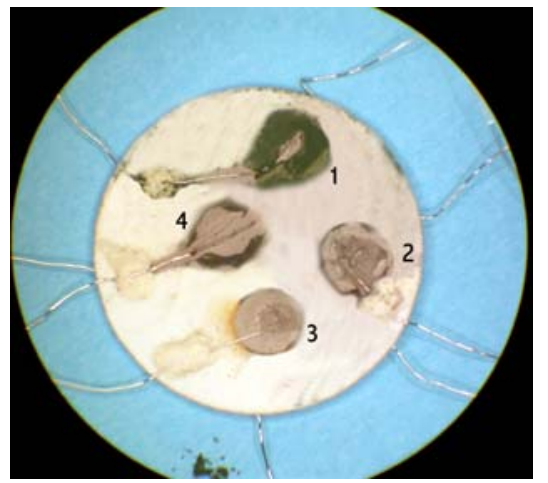

(a)

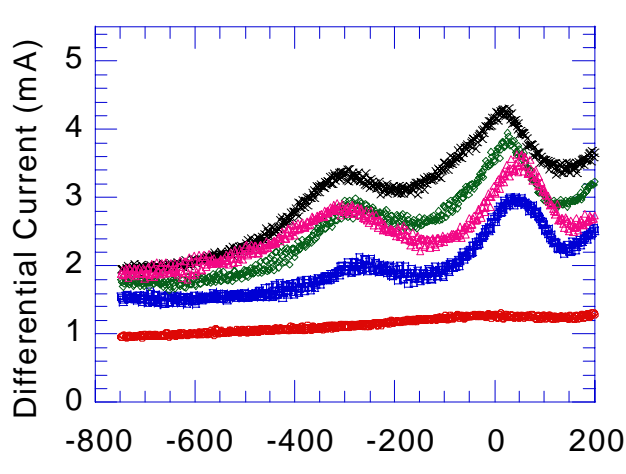

Potential $(\mathrm{mV})$ vs Pt/air reference

(c)

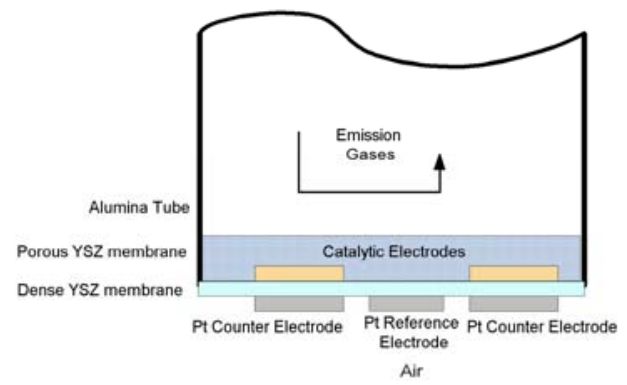

(b)

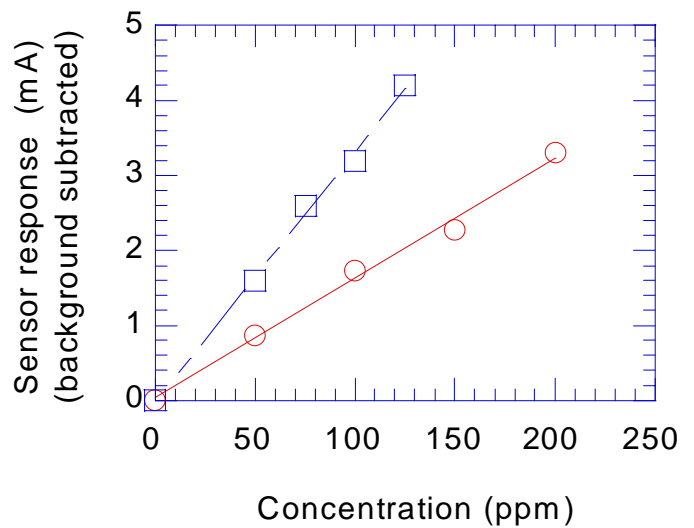

(d)

Figure E1. A photograph of a sensor with multiple elements (a), schematic diagram (b), response of the LSF sensor to NO (0-200 ppm) and CO (0-125 ppm) (c), and the calibration plot (d). 
- We have successfully demonstrated that pollutant gases such as $\mathrm{NO}, \mathrm{NO}_{2}$, and $\mathrm{CO}$ can be detected in the presence of excess $\mathrm{O}_{2}$ in a solid-state electrochemical cell using pulse voltammetric techniques on a catalytic electrode. $\mathrm{NO}_{2}$ and $\mathrm{NO}$ can be detected on either $\mathrm{CdMn}_{2} \mathrm{O} 4$ or $\mathrm{NiCr}_{2} \mathrm{O}_{4}$ electrodes in a diffusion-restricted cell. $\mathrm{CO}$ and $\mathrm{NO}$ can be detected on an LSF electrode as shown in Figure E1. Because the potentials that peaks appear are different, the species can be easily identified in the voltammogram. The calibration plots obtained for each of these gases on the respective electrodes showed excellent linearity, indicating that the technique can be used reliably to monitor exhaust gas streams.

- The solid-state electrochemical cell and the electrode design were critical for obtaining sensitivity and selectivity. As the diffusion of gases to the catalytic electrode must be restricted to obtain mass transfer control in the electrochemical reactions, a simple cell design with a catalytic electrode did not provide adequate sensitivity or selectivity for the detection of emission gases. Because mass transfer rate is quite high in the gas phase, the charge transfer rate was not sufficient to establish a mass transfer-controlled reaction, and thus the cell current did not reach a plateau as would be the case in typical aqueous solutions.

- We have proposed a mechanism for selectivity of the species, based on mixed potential at the electrochemical interface. From pulse electrochemical measurements and $\mathrm{AC}$ impedance analysis, we believe that the species are preferentially adsorbed on the catalystelectrolyte interface, and thus change the response of the electrode to the voltage waveform. Depending on the bias of the electrode, the activities of the species adsorbed are different, and thus multiple species can be detected on a single electrode. 


\section{INTRODUCTION}

\section{Purpose of the Project and Project Objectives}

Sensors can provide the electrical power industry with increased operational efficiency, reduced emissions, and lower operating costs. Advances in robust sensing and control algorithms can accelerate the time to the full-scale commercial implementation of novel power generation technologies such as advanced combustion, gasification, and turbines. Whereas the monitoring of oxygen content is the primary method of optimization of the combustion process, emission control also requires monitoring of $\mathrm{NO}_{x}, \mathrm{SO}_{\mathrm{x}}, \mathrm{CO}$, and hydrocarbons (HC). For closedloop control, fast-response, reliable sensors are needed near the combustion zone. However, the harsh conditions prevalent in the conversion of fossil fuel to energy create a barrier to making many of the desired measurements. These conditions include high temperatures (up to $1000^{\circ} \mathrm{C}$ ), elevated pressures (up to $500 \mathrm{psi}$ ), corrosive environments, and high particulate loading.

To address the critical need of on-line emission monitoring in advanced fossil fuel energy production systems, SRI International (SRI) is developing an array of miniature solid-state electrochemical sensors that are reliable, rugged, and inexpensive. These sensors, which are based on solid-state ionic conducting materials and catalytic materials, could be used for on-line, real-time detection of $\mathrm{O}_{2}, \mathrm{NO}_{x}, \mathrm{SO}_{x}, \mathrm{HC}$, and $\mathrm{CO}$ in exhaust gases.

In general, most high-temperature gas sensors operate on the principle that change in gas composition is related to a corresponding change in property such as potential, current, capacitance, or resistance. The sensors being developed in this research project measure potential (potentiometric) and/or current (amperometric and voltammetric) in a solid-state electrochemical cell. The sensor array consists of a series of electrochemical cells fabricated with yttria-stabilized zirconia (YSZ) solid-state electrolyte and catalytic working electrodes. Each working electrode material is designed to be selective to a specific gas in the gas mixture, and the sensor materials must also be stable in the operational environment for a period up to 1 year. Gases are selectively detected by application of fast-pulse voltammetric techniques on the specific catalytic electrodes optimized for the gas of interest. The configuration and geometry of the electrode are critical for obtaining the best sensor response. Thus, the research work reported here has included fabrication of ceramic electrochemical cell components with controlled microstructure to increase the selectivity, sensitivity, and response time of the sensor.

The research program consists of two phases. Phase I, which is the focus of this report, includes the proof of concept and preliminary demonstration of multiple sensors. Phase II will involve in-depth analysis and testing of sensor arrays for stability, sensitivity, and selectivity; prototype development and testing; and identification of pathways for use of integrated sensor systems in fossil fuel energy conversion systems. Successful completion of this research program will provide an economical method for monitoring emission gas in fossil energy applications. The ability to manufacture and install reliable sensor systems with high stability, high reliability, and long service life at a low cost will significantly improve clean energy generation technology and will help reach the goals of the DOE NETL Instrumentation Sensor and Control Systems Program - real-time monitoring, diagnostics, and control, which are critical for the safe and efficient operation of energy conversion systems. 


\section{Current State of Knowledge and Technology}

Advanced coal combustion systems such as pressurized fluidized-bed combustors (PFBCs) are capable of producing electricity at significantly higher efficiencies than conventional coalfired boilers. Although the fluidized bed combustor reduces the generation of thermal $\mathrm{NO}_{\mathrm{x}}$, it produces nitrogen oxides ( $\sim 200 \mathrm{ppm})$ because of the conversion of fuel-bound nitrogen. Oxides of sulfur $\left(\mathrm{SO}_{2}\right.$ and $\left.\mathrm{SO}_{3}\right)$ are also produced during the combustion processes, and they can be as high as $0.5 \%$ of the combustion gases, depending on the sulfur level of the coal.

In a PFBC, coal and air are introduced into a high-pressure reactor along with sulfur-capture agents such as dolomite. The ash and hot gases leaving the reactor are passed through cyclones and ceramic filters to remove the ash. The hot gases are then sent to a gas turbine to produce electricity. In second-generation PFBC systems, coal is pyrolyzed initially to produce a fuel gas, and the char is then sent to the combustor. The fuel gas is burnt in a gas turbine to produce additional electricity.

Emission gases can be monitored on line after most of the ash particulates have been removed by the cyclones and barrier filters. Advanced ceramic barrier filters have been demonstrated to operate at about $500^{\circ} \mathrm{C}$, and they could operate at even higher temperatures with continued research and development of the filter technology. No significant changes in the concentration of nitrogen and sulfur oxides are expected during passage through the ceramic barrier filters. Recent developments in high-temperature gas sensing mostly concern sensors that measure potential (potentiometric) and/or current (amperometric and voltammetric) in a solidstate electrochemical cell; thus, the discussion below focuses on current knowledge about such devices.

Potentiometric Gas Sensors. One early development in the field of high-temperature gas sensing technology was the potentiometric oxygen sensor used in the automotive industry; that sensor measures the open-circuit potential generated by the difference in the exhaust-gas oxygen partial pressure relative to a reference gas, which is usually air (1-3). Yttria-stabilized zirconia (YSZ) has been the electrolyte of choice because it is an oxygen ion conductor. Pt has been used as the working electrode material in many designs because it yields nearly reversible oxygen chemistry and catalyzes the oxidation of many gaseous species. The simple potentiometric cell used for oxygen sensing is $\mathrm{O}_{2}\left(P_{O 2}\right), \mathrm{Pt} / \mathrm{ZrO}_{2}\left(\mathrm{Y}_{2} \mathrm{O}_{3}\right) / \mathrm{Pt}_{2} \mathrm{O}_{2}\left(P_{O 2}{ }^{\prime \prime}\right)$, where $P_{O 2}$ ' and $P_{O 2}{ }^{\prime \prime}$ represent two different partial pressures of oxygen. Oxygen molecules acquire electrons at the electrodeelectrolyte boundary and migrate into the electrolyte as oxide anions to occupy the vacant lattice sites, which gives rise to an electrochemical $(\triangle E)$ potential given by

$$
\Delta E=(R T / n F) \ln \left(P_{O 2^{\prime}} / P_{O 2}{ }^{\prime \prime}\right)
$$

where $\mathrm{R}$ is the gas constant $\left(8.314 \mathrm{~J} \mathrm{~mol}^{-1} \mathrm{~K}^{-1}\right)$, $\mathrm{T}$ is the absolute temperature $(\mathrm{K}), \mathrm{n}$ is number of electrons per mol, and $\mathrm{F}$ is the Faraday constant $\left(96480 \mathrm{C} \mathrm{mol}^{-1}\right)$.

When the electrolyte is impermeable to oxygen molecules and when conduction through YSZ is totally ionic, the electrodes behave in a reversible manner, and each electrode is in a thermodynamic equilibrium with the adjacent electrolyte and gas (3). Such sensors, with some modifications, are used for the control of the air/fuel ratio of combustion engines and can be operated at temperatures above $600^{\circ} \mathrm{C}(4)$. 
Potentiometric devices for high-temperature gas sensing have advanced beyond their initial application for $\mathrm{O}_{2}$ detection. Catalytic metal oxides have been tested as sensor electrodes for gas sensing in different environments under potentiometric conditions using the YSZ electrolyte. Limited selectivity has been achieved by selection of a proper oxide for the application desired. For instance, the differences in emf responses for $200 \mathrm{ppm} \mathrm{NO}$ and $200 \mathrm{ppm} \mathrm{NO}_{2}$ in air at $700^{\circ} \mathrm{C}$ at sensors based on the oxides $\mathrm{CrMn}_{2} \mathrm{O}_{4}, \mathrm{ZnCr}_{2} \mathrm{O}_{4}, \mathrm{NiCr}_{2} \mathrm{O}_{4}$, and $\mathrm{ZnFe}_{2} \mathrm{O}_{4}$ are approximately 3 , 8,14 , and $43 \mathrm{mV}$, respectively. In the absence of any metal oxide, the two gases showed similar emf values at the Pt electrode, suggesting the necessity of a modifier for preferential detection. The emf values associated with metal oxides indicate that $\mathrm{ZnFe}_{2} \mathrm{O}_{4}$ is best at differentiating $\mathrm{NO}_{2}$ and $\mathrm{NO}$ among many other spinel-type oxides (5). Using impedance measurements, a $\mathrm{ZnCr}_{2} \mathrm{O}_{4}$ based electrode has been used to detect the total $\mathrm{NO}_{\mathrm{x}}$ content at $700^{\circ} \mathrm{C}(6)$.

Among other potentiometric devices, $\mathrm{CuO} / \mathrm{ZnO}$ layers deposited on $\mathrm{Pt}$ electrodes are able to detect $\mathrm{CO}$ at temperatures around $500^{\circ} \mathrm{C}(7)$. The $\mathrm{MnO}_{2}$-added $\mathrm{In}_{2} \mathrm{O}_{3}$ electrode has shown larger mixed potentials for hydrocarbons and smaller values for $\mathrm{H}_{2}$ and $\mathrm{CO}$, showing preferential detection of hydrocarbons (8). Addition of $\mathrm{SrCe}_{0.95} \mathrm{Yb}_{0.05} \mathrm{O}_{3-\alpha}(\mathrm{SCY})$, an ionic conductor, to the Pt sensing electrode has further improved the sensitivity for hydrocarbons over other reducing gases (9).

Although individual gas detection with metal oxide-based potentiometric sensors has been possible, their use has not improved selectivity significantly, despite the many modifications discussed above. Thus, it is not possible to simultaneously detect a combination of gases using potentiometric approaches. Furthermore, adsorption of the gas under investigation and the kinetics of the electrode reaction are relatively complex because of the presence of the modified electrode/electrolyte/gas multiple phase boundaries. Consequently, gases are not necessarily in thermodynamic equilibrium (i.e., they do not obey the Nernstian relationship) at the electrode surface and at the other interfaces, resulting in mixed potentials. Mixed potentials depend strongly on catalytic and electrocatalytic properties. These complications, together with sintering effects and surface poisoning problems, cause the sensor signal to drift, resulting in erroneous results. Therefore, more accurate, sensitive, and selective analytical devices are needed for the simultaneous detection of gases under harsh conditions such as those in fossil fuel energy conversion systems.

Amperometric Gas Sensors. Another aspect of electrochemical detection entails monitoring electrochemical activity of different analytes at selective operational potentials by measuring the resulting current (i.e., amperometric detection). $\mathrm{NO}$ and $\mathrm{NO}_{2}$, both at $200 \mathrm{ppm}$ and in the presence of $\mathrm{O}_{2}$, showed mixed potentials at $-15 \mathrm{mV}$ and $+45 \mathrm{mV}$, respectively, for a $\mathrm{CdCr}_{2} \mathrm{O}_{4} / \mathrm{Pt}$ potentiometric device at $550^{\circ} \mathrm{C}$, indicating that the oxidation of $\mathrm{NO}$ and the reduction of $\mathrm{NO}_{2}$, as given below, can be detected at two different potentials (10).

$$
\mathrm{NO}_{2}+2 \mathrm{e} \rightarrow \mathrm{NO}+\mathrm{O}^{2-} \quad \mathrm{NO}+\mathrm{O}^{2-} \rightarrow \mathrm{NO}_{2}+2 \mathrm{e}
$$

However, $\mathrm{NO}$ sensitivity is much less than that of $\mathrm{NO}_{2}$ even at $\mathrm{CdCr}_{2} \mathrm{O}_{4}$-attached $\mathrm{Pt}$ electrodes, making it impossible to detect the two gases selectively in a gas mixture using potentiometric devices $(11,12)$. This drawback has been overcome by amperometric detection, where the preferential reduction of $\mathrm{NO}_{2}$ has been possible at $-60 \mathrm{mV}$, while the preferential oxidation of $\mathrm{NO}$ is performed at $+100 \mathrm{mV}$ on a single $\mathrm{CdCr}_{2} \mathrm{O}_{4} / \mathrm{Pt}$ electrode. It should be noted that common amperometric sensors operate in the diffusion-limited mode and that each molecule 
passing the diffusion barrier reaches the interface for immediate reaction, generating a current given by the following relationship.

$$
I_{\text {lim }}=\left[n F D_{G} P_{t o t} A / R T L\right] \ln \left(1-x_{G}\right)
$$

where $I_{\text {lim }}$ is the diffusion-limited current; $n$ is the number of electrons associated with the electrochemical reaction; $F$ is Faraday's constant; $D_{G}$ is the diffusion coefficient of the gas, $\mathrm{G} ; A$ is the surface area of the electrode; $R$ is the gas constant; $T$ is the temperature of detection; $L$ is the diffusion length; and $x_{G}$ is the mole fraction of $G$. This relationship clearly indicates the analytical utility of amperometry.

The presence of $\mathrm{CdCr}_{2} \mathrm{O}_{4}$ has been crucial for enhancing $\mathrm{NO}$ selectivity, provided that a suitable anodic potential is selected for its detection. At the NO detecting potential, interference effects from $\mathrm{CO}_{2}, \mathrm{CH}_{4}, \mathrm{H}_{2}$, and $\mathrm{CO}$ were found to be negligible, whereas at the $\mathrm{NO}_{2}$ detecting potential, interference from $\mathrm{CO}_{2}, \mathrm{CH}_{4}$, and $\mathrm{H}_{2}$ was negligible. However, the use of oxidemodified electrodes in amperometric detection is still in its early stages and has not received widespread attention to date.

Interference of Oxygen with Analyte Sensitivity. The effect of oxygen on the detection of other gases was recently investigated, and dual-electrode configurations have been reported for the determination of nitrogen oxides or other emission gases, in the presence of $\mathrm{O}_{2}$, at high temperatures $(12,13)$. In all the configurations designed to date, it has been necessary to reduce $\mathrm{O}_{2}$ completely at the first electrode, but prevent the reduction of the second species. The gas reaching the second electrode is therefore free of $\mathrm{O}_{2}$. As such, the most crucial part of this arrangement is the first electrode. The dual-electrode configuration is more sensitive than the single-electrode amperometric sensor, and the application improves the selectivity. As the interfering gas components are removed at the first electrode by electrochemical filtering, selectivity and sensitivity are considerably improved. However, this design does not provide a means of independent detection of multiple emission gases (e.g., $\mathrm{NO}_{\mathrm{x}}$ and $\mathrm{SO}_{\mathrm{x}}$ ). In addition, interference with detecting one analyte from the other constituents in the sample has been detected when some constituents are present above a certain threshold concentration.

\section{SRI's Innovative Approach}

We are designing sensors based on a combination of amperometric and fast, differential pulse voltammetric techniques, and on an array of electrocatalytic electrodes. These techniques offer higher sensitivity than other electrochemical techniques, as shown in Table 1. Figure 1 presents a conceptual design for the sensor array. The sensors are designed with a diffusion channel and, if necessary, with a relatively large first electrode so that oxygen can be electrochemically filtered. Subsequent sensor electrodes will be designed to provide high selectivity and sensitivity for a specific gas in the combustion exhaust.

Figure 2 depicts a typical waveform and the resulting current signal of a fast differential pulse voltammetric experiment. The entire waveform is applied on a sensor electrode in less than a second, and thus multiple sweeps are possible for signal averaging to increase the signalto-noise ratio. If the interested components in the gas mixture have enough separation in their redox potentials, theoretically they can be resolved in a single electrode. However, in most applications, the complexity of gas mixtures precludes a complete analysis using a single device. Therefore, multiple electrodes, each with unique catalytic properties for a particular component, 
are used to resolve and determine the concentration of individual components. For example, for a mixture of gases $\mathrm{A}, \mathrm{B}$, and $\mathrm{C}$, the first sensor element may resolve $\mathrm{A}$ from $\mathrm{B}$ and $\mathrm{C}$, whereas the second sensor element resolves B from A and C, and so on as shown in Figure 2b. Selectivity and sensitivity for specific gases are achieved by proper selection of potential program parameters and electrocatalytic material for the sensor element.

Table 1: Typical levels of detection of electrochemical methods.

\begin{tabular}{|l|l|}
\hline \multicolumn{1}{|c|}{ Method } & Level of detection, $\mathbf{M}$ \\
\hline Potentiometry & $10^{-3}$ \\
Voltammetry (linear sweep) & $10^{-3}-10^{-4}$ \\
Amperometry (steady state) & $10^{-5}-10^{-6}$ \\
Amperometry (flow injection mode) & $10^{-7}-10^{-9}$ \\
Pulse voltammetry & $10^{-8}$ \\
Differential pulse voltammetry & $10^{-9}$ \\
\hline
\end{tabular}

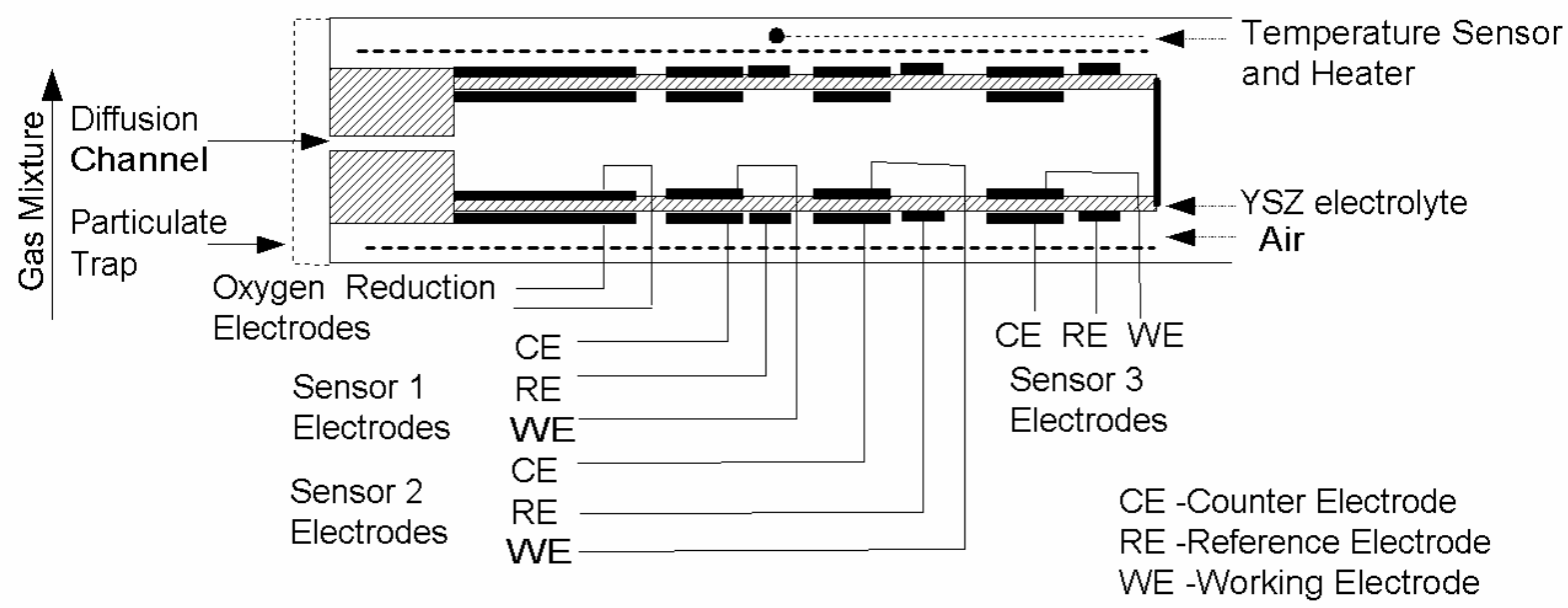

Figure 1. Conceptual design of a sensor array for simultaneous multicomponent gas analysis. 


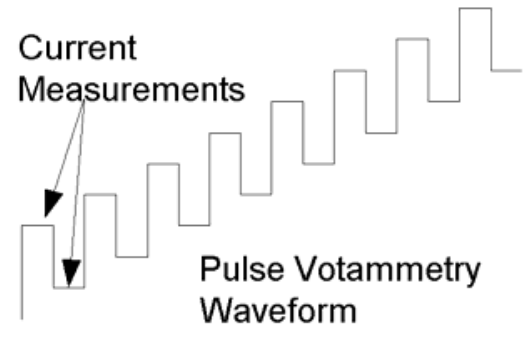

(a)
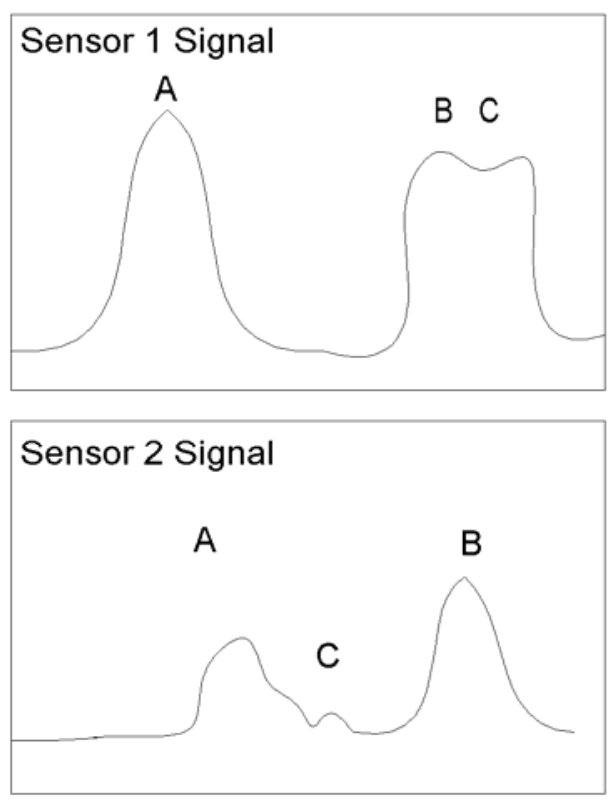

(b)

Figure 2. A typical differential pulse voltammetry waveform (a) and sensor response (b).

Selection of materials for sensor elements and fabrication techniques are of utmost importance for achieving the desired selectivity and sensitivity. The sensitivity and selectivity of an electrode material depends not only on the type of material, but also on the electrode's microstructure, configuration, and geometry. The ionic conductivity of the electrolyte is also important for achieving fast device response. Thus, our Phase I research work focused on selection and synthesis of suitable catalytic materials for detecting $\mathrm{NO}, \mathrm{NO}_{2}$, and $\mathrm{CO}$; fabrication of YSZ ceramic membranes with controlled microstructure; preparation of catalytic electrodes; electrochemical cell design; software development for pulse voltammetry; and testing of sensors for their sensitivity and selectivity to emission gases. 


\section{EXPERIMENTAL}

For initial evaluation, drawing on literature findings and our experience, we selected three materials, LSF, $\mathrm{CdMn}_{2} \mathrm{O}_{4}$ and $\mathrm{NiCr}_{2} \mathrm{O}_{4}$. We prepared $\mathrm{CdMn}_{2} \mathrm{O}_{4}$ and $\mathrm{NiCr}_{2} \mathrm{O}_{4}$ by solid-state synthesis methods; we purchased LSF as a ready-made paintable ink from Nextech, Inc.

We fabricated test sensors on zirconia membranes $(50-150 \mu \mathrm{m}$ thick and $1.5 \mathrm{~cm}$ in diameter) with these materials as the catalytic electrodes. Sensor fabrication involved preparation of YSZ membranes, deposition of auxiliary electrodes, deposition of catalytic electrodes and electrical contacts, and mounting of the cell in the test housing. The sensors were then tested under a variety of conditions for their sensitivity and selectivity to $\mathrm{NO}, \mathrm{NO}_{2}$, and $\mathrm{CO}$ gases.

\section{Synthesis of $\mathrm{CdMn}_{2} \mathrm{O}_{4}$}

To synthesize $\mathrm{CdMn}_{2} \mathrm{O}_{4}, \mathrm{CdO}$ powder $(6.4 \mathrm{~g})$ and $\mathrm{MnO}_{2}$ powder $(8.7 \mathrm{~g})$ were mixed and ball milled for 12 hours. The powder was pressed into a pellet and sintered at $1000^{\circ} \mathrm{C}$ for 6 hours in a high-temperature furnace. After sintering, the pellet was crushed, ball milled for 12 hours, and pressed into a pellet and sintered again at $1000^{\circ} \mathrm{C}$ for 6 hours. The powder was analyzed by $\mathrm{X}$-ray diffraction (XRD) to confirm the phase structure.

\section{Synthesis of $\mathrm{NiCr}_{2} \mathrm{O}_{4}$}

To synthesize $\mathrm{NiCr}_{2} \mathrm{O}_{4}, 3.75 \mathrm{~g}$ of $\mathrm{NiO}$ and $7.6 \mathrm{~g}$ of $\mathrm{Cr}_{2} \mathrm{O}_{3}$ were mixed, ball milled for 12 hours, and pressed into a pellet. The pellet was sintered at $1400^{\circ} \mathrm{C}$ for 6 hours in a hightemperature furnace. The process was repeated two times. The phase identification of the compound was confirmed by XRD analysis.

\section{Fabrication of YSZ Membranes}

The sensors were fabricated on YSZ membranes, which serve as the electrolyte. The base zirconia discs (electrolyte) were prepared by tape casting. That procedure is similar to the one used in the commercial fabrication of multilayer capacitors. Briefly, a slip of YSZ powder in an organic liquid mixture of xylene and ethanol was prepared with a small amount of LCP Menhaden oil as a dispersant, polyvinyl butyral (PVB) as a binder, benzyl butyl phthalate (BBP) as a plasticizer, and polyethylene glycol (PEG) as a release agent. The slip was then cast into a tape using a doctor blade. To obtain porous ceramic layers, the slips were prepared with added pore formers, such as spherical carbon and graphite particles.

Xylene and ethanol solvents vaporized from the cast tape at ambient temperature, yielding a flexible dry tape that can be handled ("green" tape). For some sensor designs, we laminated a dense YSZ layer to a porous layer. The cells were cut from the green tape using a laser and heated in air at a controlled rate to $1400^{\circ} \mathrm{C}$. The temperature program involved several steps for solvent evaporation, binder burnout, and sintering. The temperature program of the furnace is critical for obtaining defect-free, flat zirconia discs. Approximately $30 \%$ shrinkage occurs in the dimensions of the cells during sintering. 


\section{Fabrication of Sensors}

The sensors were fabricated on YSZ membranes, which served as the electrolyte. The base zirconia membranes (electrolyte) were prepared by tape casting. The electrolyte was painted on one side with Pt ink and on the other side with the catalytic material (e.g., $\mathrm{CdMn}_{2} \mathrm{O}_{4}$ ) and fired at $850^{\circ} \mathrm{C}$ for 1 hour. Some sensors were made with all Pt electrodes. In the latter part of Phase I, the catalytic electrode sintering temperature was reduced to $750^{\circ} \mathrm{C}$, and the sintering time was increased to 3 hours. The electrical contacts to the electrodes were made with fine Pt wires $(0.1$ $\mathrm{mm})$. The contact wires were held in place by small amount of high-temperature cement (Aremco). Figures 3 and 4 show the single and multielectrode sensor designs, respectively, that we used in most experiments. In both cases, the counter electrode was painted to be about the same size as the catalytic electrode, and it was placed on exactly the opposite side of the catalytic electrode. The reference electrode was offset from the counter electrode by at least 3 times the thickness of the electrolyte. We fabricated numerous variations of this basic design to optimize the selectivity and sensitivity of the sensors. The sensors were mounted to an alumina tube using Aremco cement as shown in Figure 5. The sensor element end of the tube was placed in a hightemperature furnace. We performed the initial testing at between $500^{\circ}$ and $800^{\circ} \mathrm{C}$.
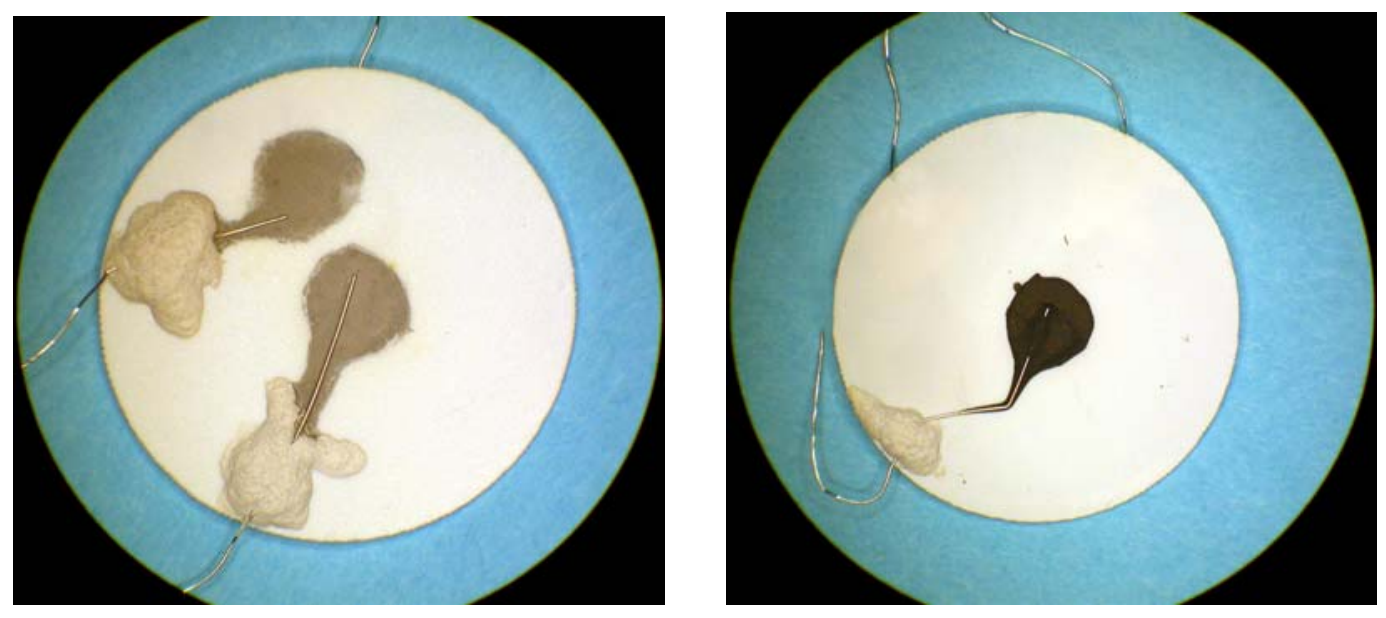

Figure 3. Photographs of a single sensor, Pt counter and reference electrodes (left) and catalytic working electrode (right). The contact wires are held in place with a dab of cement. 

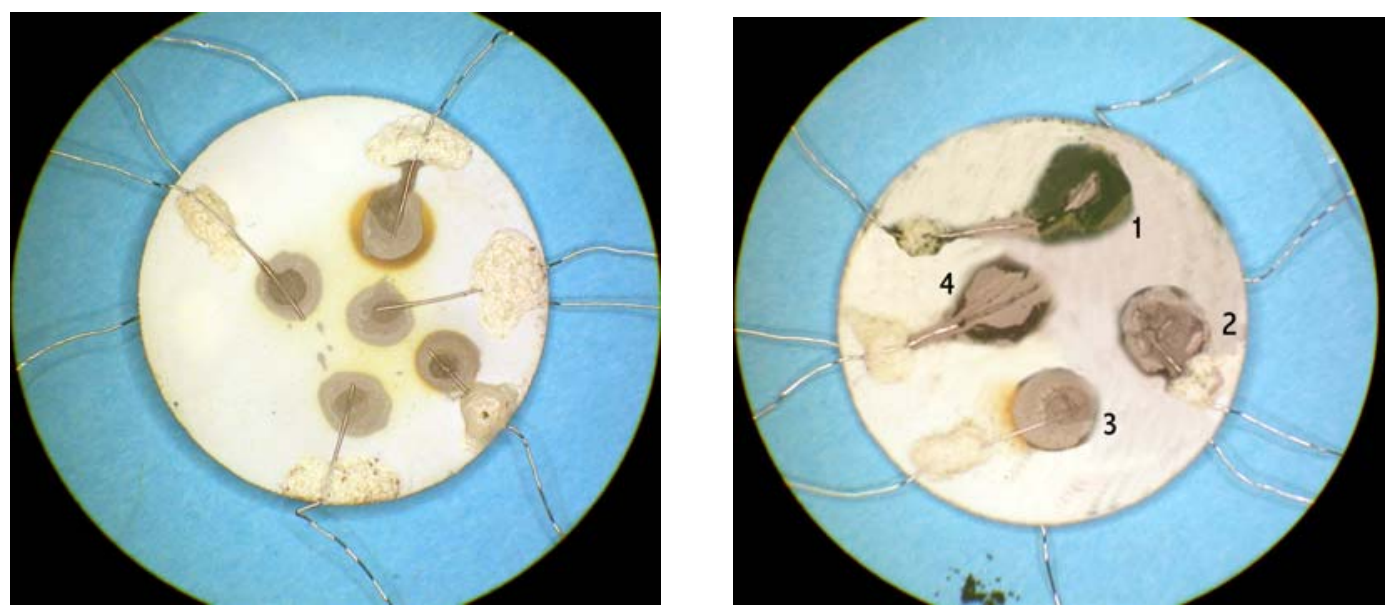

Figure 4. Photographs of a multielectrode design; Pt counter electrodes and the reference electrode in the center (left), and catalytic electrodes (right). Catalytic electrodes: $1-\mathrm{NiCr}_{2} \mathrm{O}_{4}, 2-\mathrm{LSF}, 3-\mathrm{Pt}$, and 4- $\mathrm{CdMn}_{2} \mathrm{O}_{4}$.
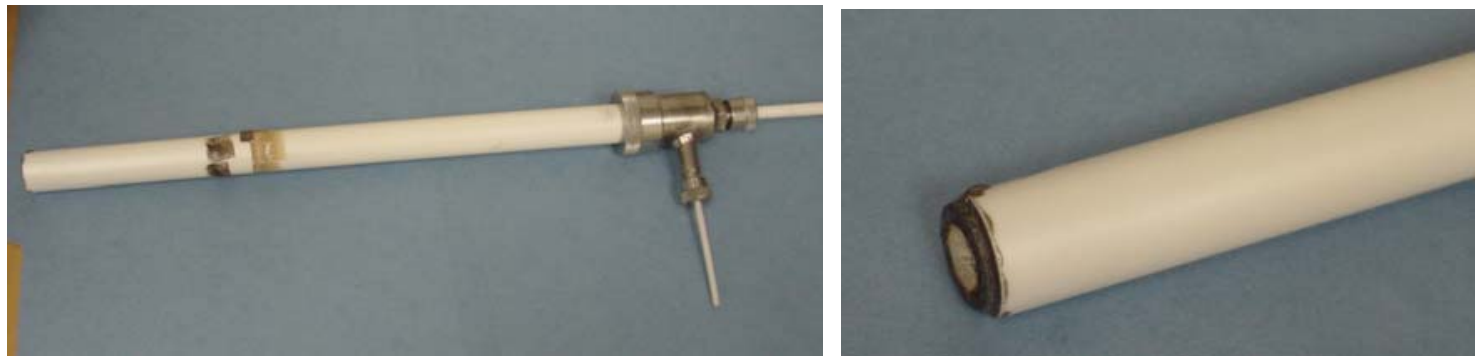

Figure 5. Photographs of the sensor housing assembly (left) and the sensor element end (right).

\section{Sensor Test Station}

Figure 6 shows a schematic diagram of the experimental setup that we used to test the sensors. The gas flow to the sensor assembly is controlled by four mass flow meters. The gas compositions can be varied by setting the mass flow controllers to the necessary flow. The mass flow controller unit (Aalborg) is interfaced with the computer via a RS 232 serial communication port. The potentiostat (EG\&G-PAR283) is interfaced with a computer with a GPIB card (National Instruments). The furnace is controlled by a programmable temperature controller (Eurotherm). The sensors to be tested are mounted on the tip of an alumina tube $(16 \mathrm{~mm})$. A second alumina tube $(6 \mathrm{~mm})$ is mounted inside the large tube for the inlet gas flow to the sensor. The gases enter the sensor chamber through the inside alumina tube $(6 \mathrm{~mm})$ and exit through the outer tube and the T-joint. 


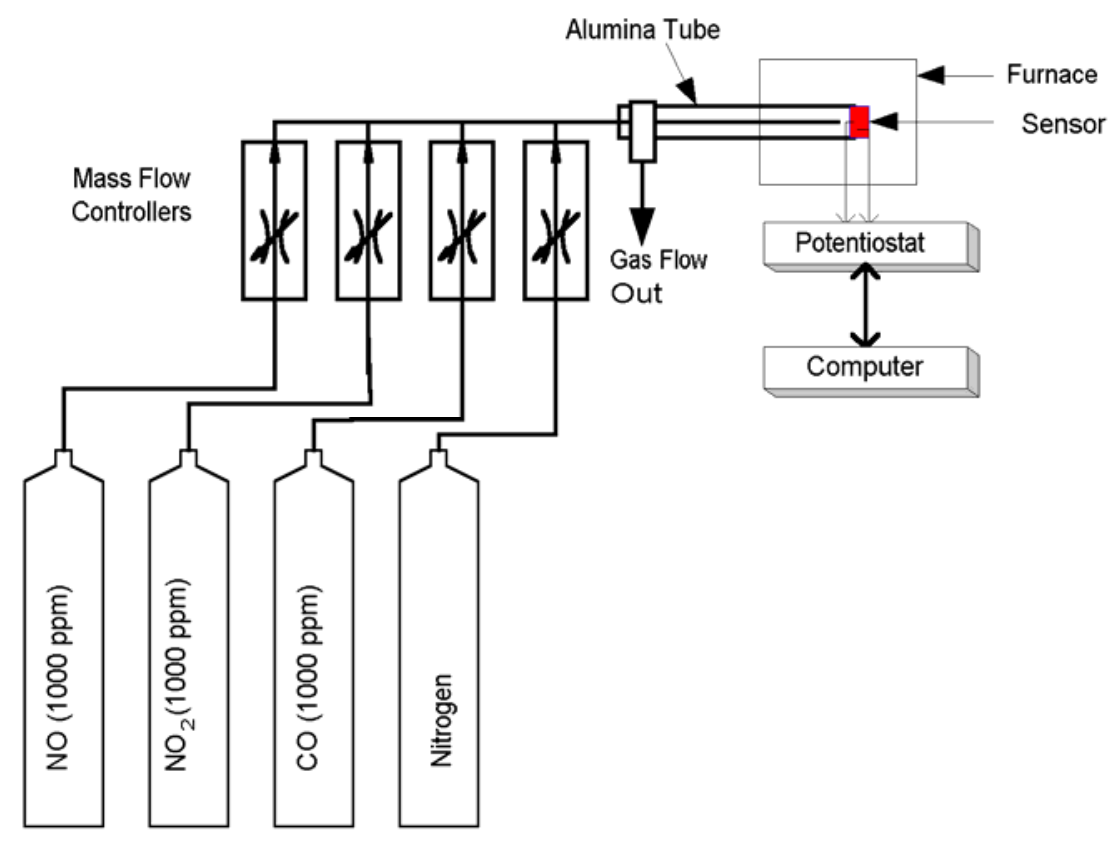

Figure 6. Experimental setup for testing sensors.

\section{Computer Program Development}

For Phase I, we used a potentiostat (EG\&G PAR Model 283) for waveform generation and data acquisition. Because the commercial software package we bought with the potentiostat did not provide sufficient flexibility for the planned experiments, we wrote the data acquisition and experiment control software in our laboratory. The computer codes for square wave voltammetry and data acquisition were developed with Microsoft Visual Basic ${ }^{\circledR}$. The main control and data acquisition computer program development was completed during Phase I.

\section{AC Impedance Analysis.}

AC impedance of sensors was determined using a phase sensitive detector (EG\&G PAR Model 1025) coupled to a potentiostat (EG\&G PAR 283). The experiments and data acquisition were performed using a commercial software package (EG\&G EIS Software Model 398). Typically, a $10 \mathrm{mV}$ perturbation in the frequency range of $10 \mathrm{kHz}$ to $0.01 \mathrm{~Hz}$ was applied to the cell at the open circuit potential, and the resulting current was measured with its phase information. Measurements were performed with and without analyte in a $2 \% \mathrm{O}_{2}$ (balance $\mathrm{N}_{2}$ ) gas stream. 


\section{RESULTS AND DISCUSSION}

\section{Electrode Materials}

In potentiometric measurements, $\mathrm{CdMnO}_{4}$ has shown selectivity to $\mathrm{NO}$ at $600^{\circ} \mathrm{C}(10)$, and $\mathrm{NiCr}_{2} \mathrm{O}_{4}$ has shown selectivity to $\mathrm{NO}_{2}$ at $650^{\circ} \mathrm{C}(11)$. Both compounds are insensitive to $\mathrm{CO}$, $\mathrm{CO}_{2}, \mathrm{HC}$, and $\mathrm{O}_{2}$ according to published literature (10-12). Therefore, we selected these compounds as candidate electrode materials for the voltammetric cell. We prepared $\mathrm{CdMn}_{2} \mathrm{O}_{4}$ and $\mathrm{NiCr}_{2} \mathrm{O}_{4}$ by solid-state synthesis methods. Figure 7 shows the XRD spectrum of the synthesized $\mathrm{CdMn}_{2} \mathrm{O}_{4}$. The XRD pattern matches well with the library spectrum of $\mathrm{CdMn}_{2} \mathrm{O}_{4}$, confirming the oxide phase structure in the compound. Figure 8 shows the XRD spectrum of the synthesized $\mathrm{NiCrO}_{4}$ compound, which also matches well with the library spectrum of $\mathrm{NiCr}_{2} \mathrm{O}_{4}$, indicating the presence of the oxide phases in the synthesized compound.

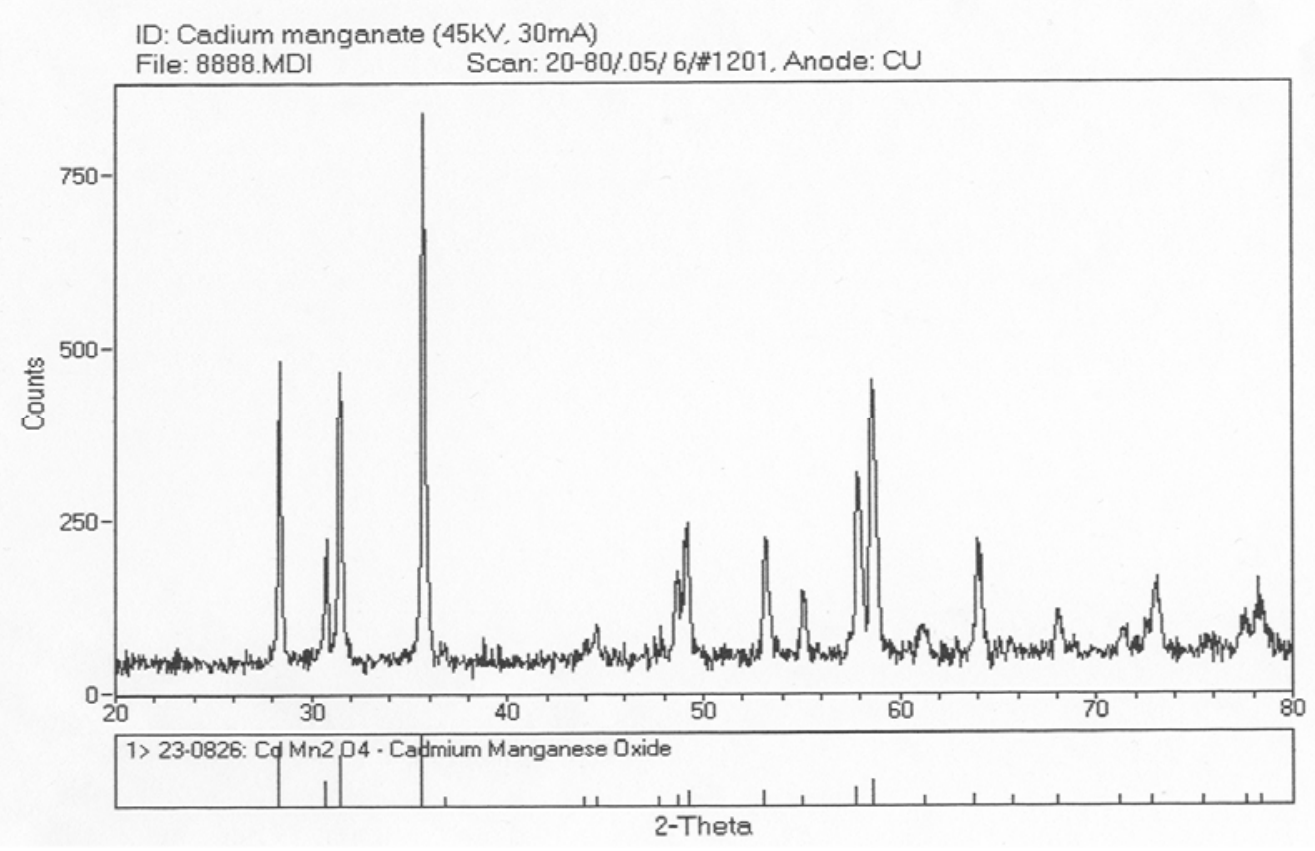

Figure 7. XRD spectrum of $\mathrm{CdMn}_{2} \mathrm{O}_{4}$ (top: synthesized, bottom: library) 


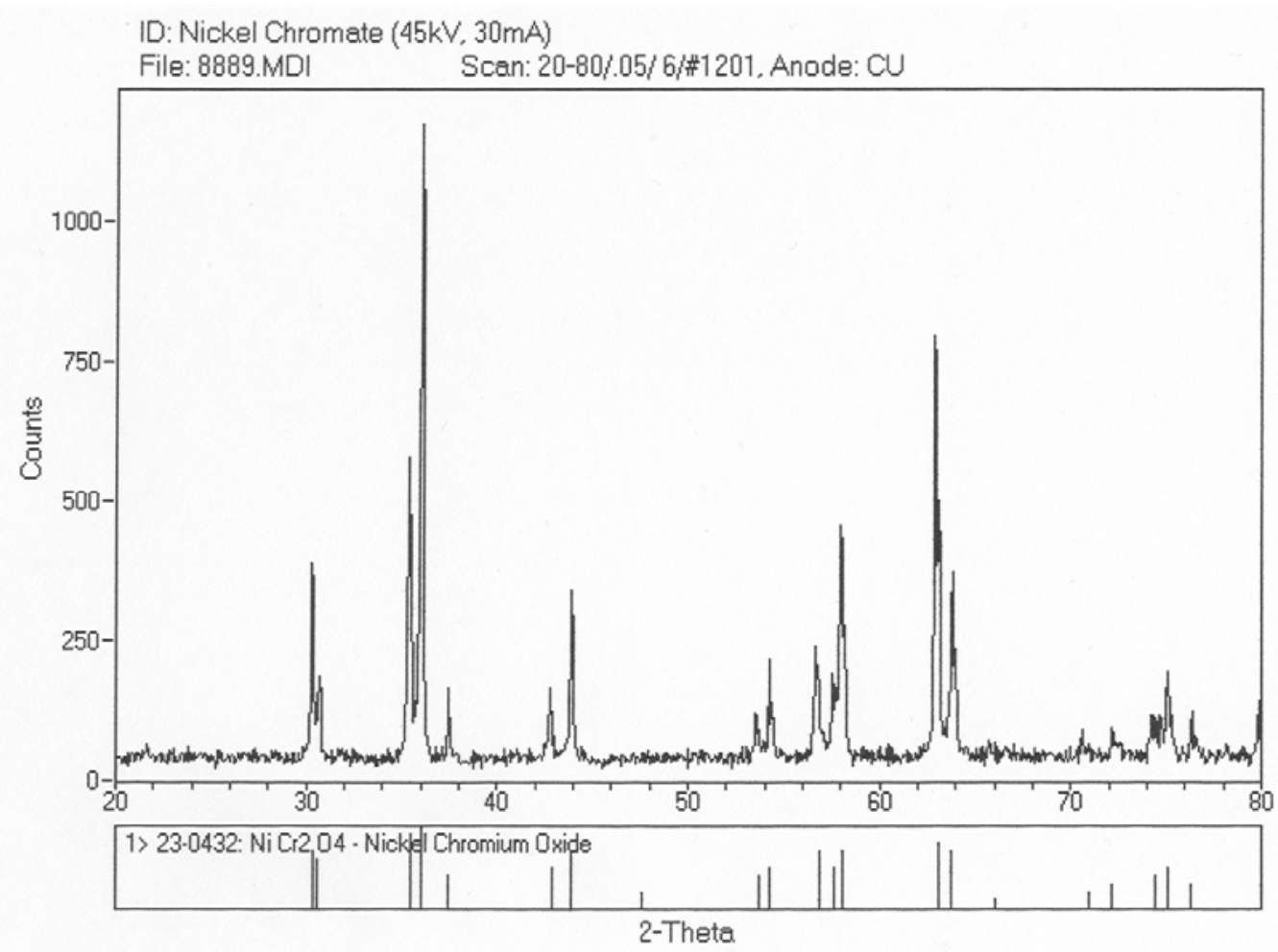

Figure 8. XRD spectrum of $\mathrm{NiCr}_{2} \mathrm{O}_{4}$ (top: synthesized, bottom: library)

\section{YSZ Membrane Fabrication}

Initially, we experienced an abnormally high rate of failure during the sintering of ceramic membranes (e.g., cracking and delamination of the membrane when we tried to fabricate multilayer membranes with porous/dense structure). Consequently, we performed thermogravimetric analysis (TGA) and differential scanning calorimetry (DSC) studies to develop an optimum heating profile to control the sintering of ceramic assemblies that would not develop cracks. Binder removal is an important processing operation in the fabrication of ceramic components, and the selection of heating rates, hold temperatures, and hold times for binder burnout is critical for maximizing the yield of final product with minimum furnace time.

During heating, the organic binder (PVB), plasticizer (BBP), and release agent (PEG) either vaporized, decomposed, or oxidized in air. The DSC experiments showed that while BBP vaporized endothermically, PEG and PVB produced an exotherm, presumably due to oxidation or decomposition of these organic chemicals (Figure 9). The heat released during the oxidation of PVB was somewhat high $(9.9 \mathrm{~kJ} / \mathrm{mole})$ but not excessive, and it occurred over a wide range of temperature. The heat of vaporization of BBP was quite low $(0.087 \mathrm{~kJ} / \mathrm{mole})$, and the heat released during PPG decomposition was moderate $(2.2 \mathrm{~kJ} / \mathrm{mole})$; both of these compounds vaporized over a narrow temperature range. 


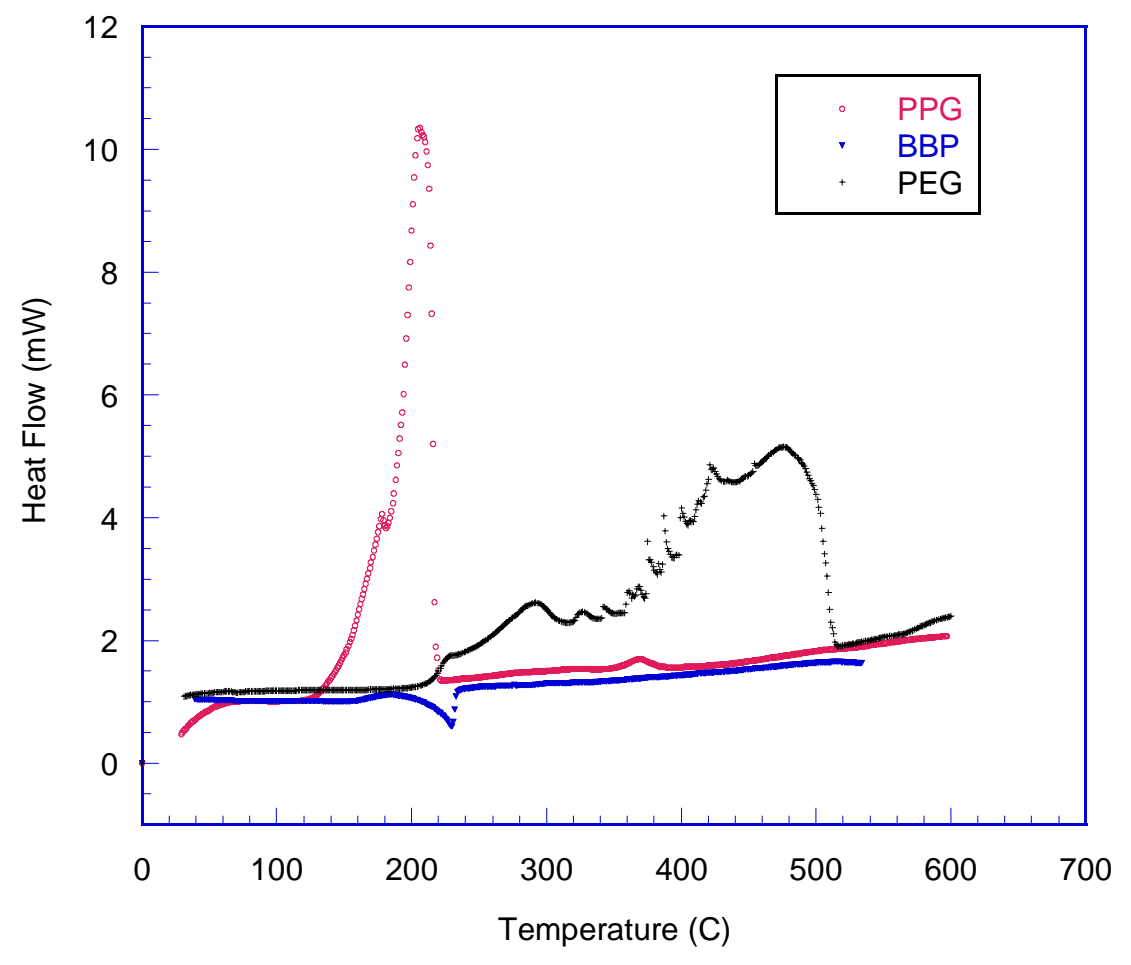

Figure 9. DSC trace of the vaporization of PPG, BBP, and PVB during heating $\left(3^{\circ} \mathrm{C} / \mathrm{min}\right)$

Figure 10 shows the mass loss that occurred during heating of these organic chemicals. The TGA results can be used to determine decomposition kinetics. Although, the results vary in the presence of YSZ, they can be used as a guide for the heating profile, and adjustments must be made to account for mass transfer limitations present in thick and large samples.

The TGA and DSC data showed that the organic chemicals in the tape began to vaporize in the temperature range $150^{\circ}$ to $270^{\circ} \mathrm{C}$; the $\mathrm{PEG}$ and the $\mathrm{PVB}$ vaporized before the $\mathrm{PVB}$ was removed. The mass loss connected with $\mathrm{BBP}$ and $\mathrm{PPG}$ occurred over a narrow temperature range, whereas that of PVB extended over a broad range of temperatures. Studies have shown that the surfaces of ceramic particles may play a catalytic role in the binder burnout (14). Hence, the data obtained with pure compounds must be modified in the presence of zirconia particles. 


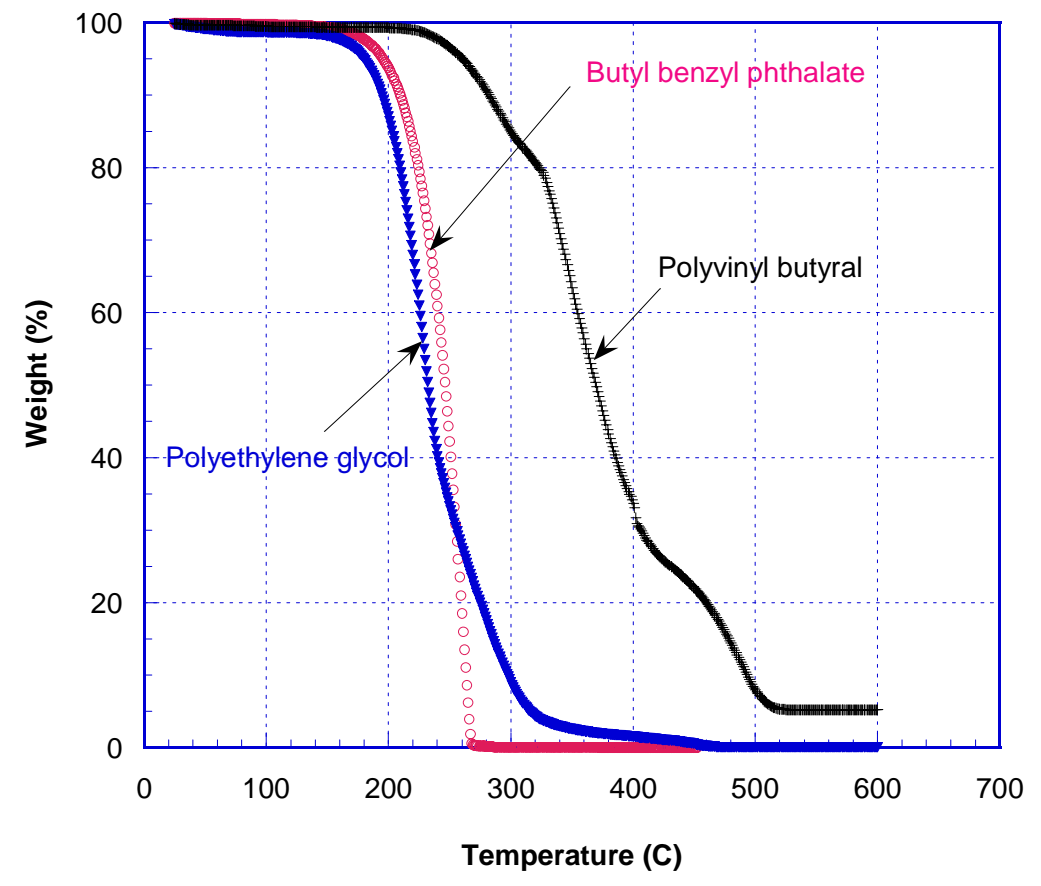

Figure 10. TGA profile of plasticizer, release agent, and binder during heating $\left(3^{\circ} \mathrm{C} / \mathrm{min}\right)$.

The TGA data obtained with our tape cast samples showed a complex mass loss profile because PPG and BBP were being removed in the same temperature range and because the decomposition of PVB occurred in more than one step. However, we used the data as a guide to develop a preliminary heating profile. If the vaporizing gases in the multilayer tape are not allowed to escape slowly, blisters and bubbles could appear during binder burnout. They occur especially when the volume fraction of the binder is sufficiently high to form a continuous film. We adjusted the heating profile so that the mass loss rate would be in the range 0.5 to 1 $\mathrm{wt} \% / \mathrm{min}$. At that rate, the binder burnout would be completed in about $10 \mathrm{~h}$.

\section{Electrode Fabrication}

Initially, we observed that the electrode material delaminated from the YSZ electrolyte surface during the electrode sintering process. This delamination was due to a thermal expansion coefficient mismatch of electrode/electrolyte materials. The problem was aggravated by the need for higher sintering temperatures for the electrode materials with large particle size. To address this problem, we lowered the sintering temperature requirements by reducing the particle size. Nanoparticles sinter at $100^{\circ}$ to $200^{\circ} \mathrm{C}$ lower than the typical sintering temperature of the same material of micron size. We started sintering all electrodes at $750^{\circ} \mathrm{C}$ for 3 hours, which appeared to produce strongly bonded catalytic electrodes. 


\section{Software Development and Testing}

We wrote the software for experimental control and data acquisition in Microsoft Visual Basic $^{\circledR}$. The software was written with prototype development in mind so that it could be easily upgradeable for prototype and commercial use. Figure 11 shows the graphical user interface window of the program. All experimental parameters are entered from this window, and the pulse waveform is calculated for downloading to the potentiostat. The waveform is displayed to visually confirm the expected potential range, pulse height, and time base. Once the operator is satisfied, the waveform codes are downloaded to the potentiostat, and the potential scan is performed. The downloaded waveform codes reside in the potentiostat memory so that fast multiple scans can be performed for signal averaging. The resulting current data are stored in the potentiostat during the scan. On completion of potential scans, data are downloaded to the control computer and displayed and saved for further analysis. Figure 12 shows a typical data output window of the program during the experiment.

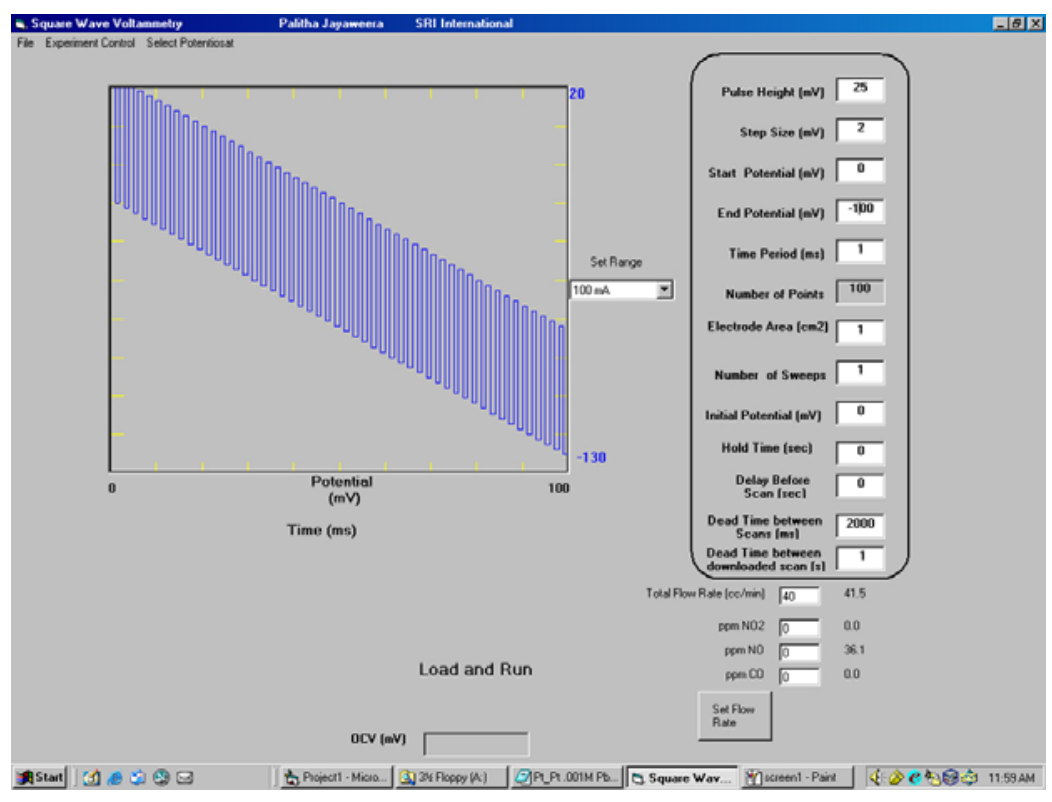

Figure 11. Graphical user interface window of the control program.

We performed a calibration/system check of the software with an aqueous electrochemical cell. We prepared an electrolyte solution of $1 \mathrm{M} \mathrm{KCl}$ with $10^{-3} \mathrm{M} \mathrm{Cd}^{2+}$ and $\mathrm{Pb}^{2+}$. The solution was purged with nitrogen for 30 min and square wave voltammetry was performed using the software and experimental setup described above. Figure 13 shows the resulting voltammogram for the $10^{-3} \mathrm{M} \mathrm{Cd}^{2+}$ and $\mathrm{Pb}^{2+}$ solution. The position of peaks and sensitivity were as expected, and thus this test confirmed the operation of software and computer interfaces. 


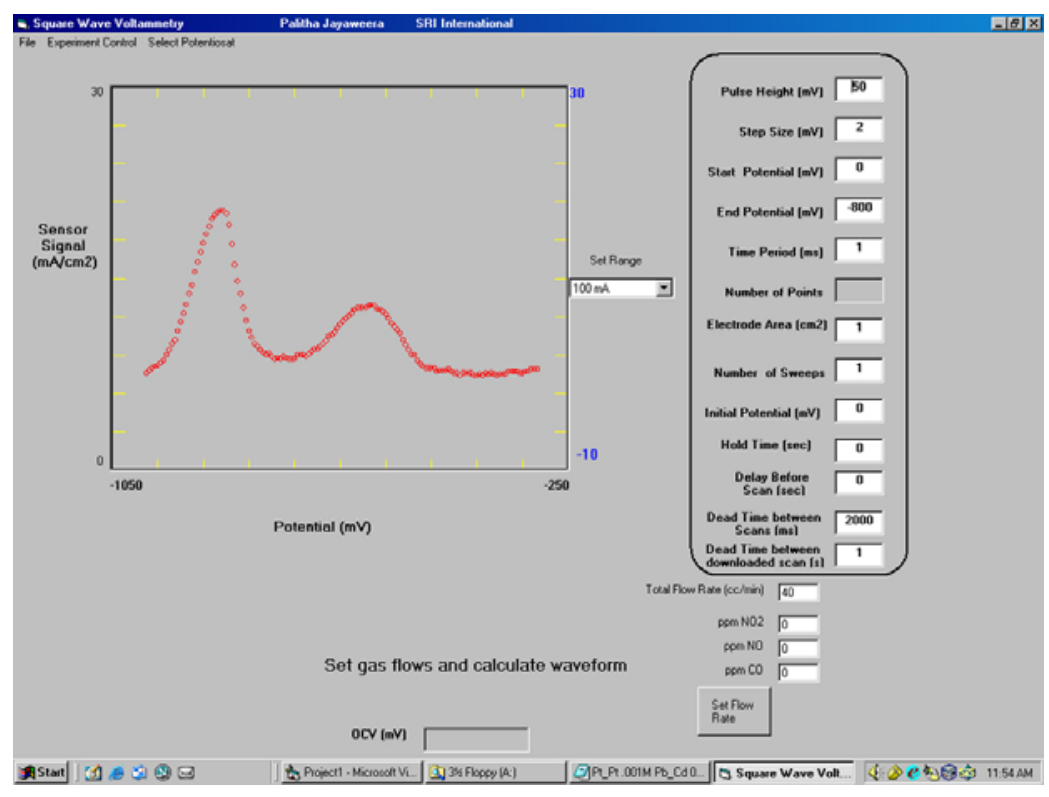

Figure 12. Data output window of the program.

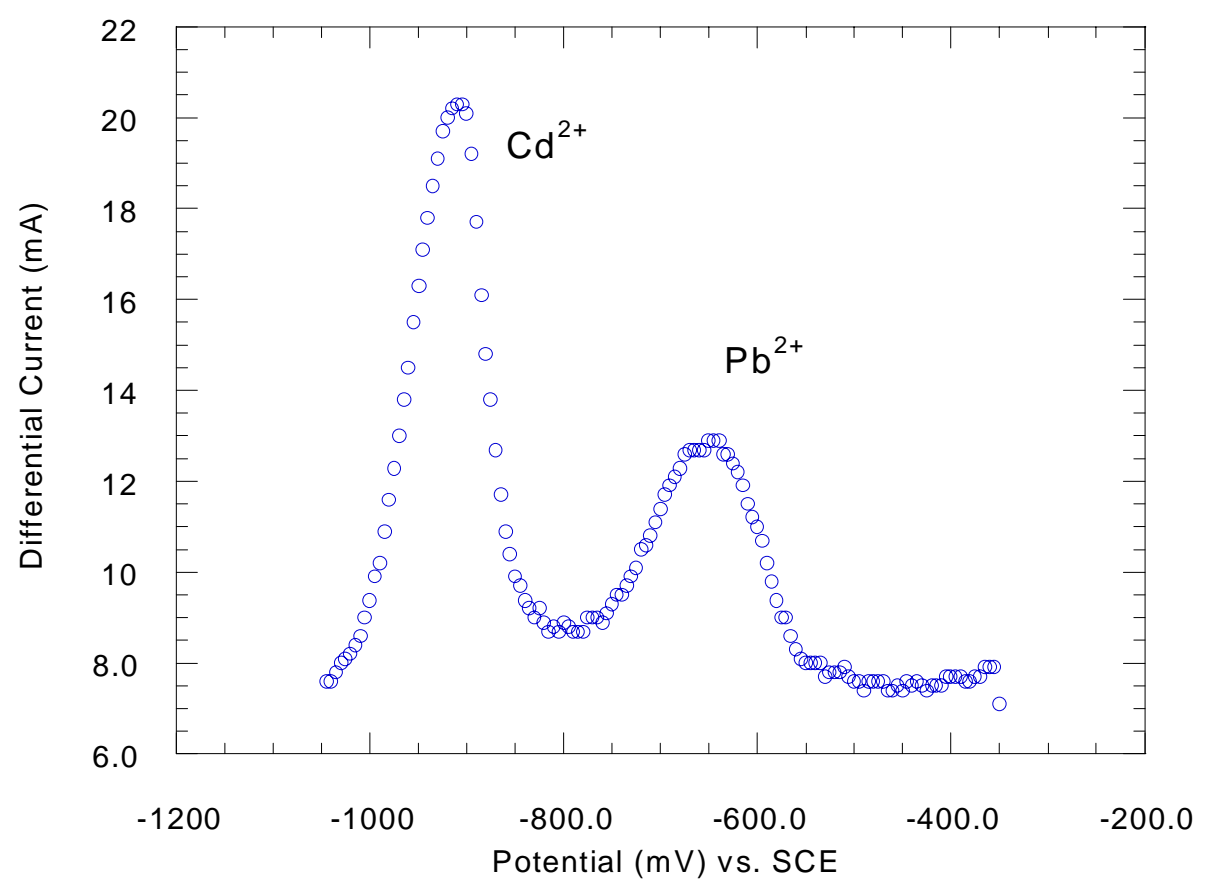

Figure 13. Square wave voltammogram for $10^{-3} \mathrm{M} \mathrm{Cd}^{2+}$ and $\mathrm{Pb}^{2+}$ solution obtained with the new software.

\section{Sensor Designs}

We fabricated and tested a number of sensor designs with $\mathrm{CdMn}_{2} \mathrm{O}_{4}, \mathrm{NiCr}_{2} \mathrm{O}_{4}$, and LSF catalytic electrodes. The sensor designs that we tested are shown in Figures 14 through 18. In the sensor design shown in Figure 14, all electrodes are in the emission gas stream. The 
advantage of this design is that the sensor does not need to be sealed to the housing, and only the electrical connections are fed through the alumina walls of the housing. In addition, the ceramic sensor elements are not attached to the housing and thus the difference in thermal expansion of materials does not result in any stress on the elements, thereby minimizing sensor failure due to thermal shock.

For pulse voltammetric measurements, a reference electrode is needed for proper operation of the electrochemical cell. The reference electrode is placed on the surface of the inactive area of the electrolyte, some distance away from the edge of the active electrodes. The only difference in designs $\mathrm{A} 1$ and $\mathrm{A} 2$ is the placement of the reference electrode. In $\mathrm{A} 1$, the reference electrode is placed on the counter electrode side, and in A2, it is placed on the working electrode side. We found that both designs yielded similar results, provided that the reference electrode was placed at a distance more than 3 times the electrolyte thickness away from the edge of the active electrodes. The reference electrode measures the electrolyte potential along the equipotential surface somewhere between the two active electrodes. After more than three times the electrolyte thickness away from the edge of the active electrodes, the potential measured is essentially the potential at the center of the electrolyte regardless of the placement side of the reference electrode. However, the disadvantage of this design is that the reference electrode potential can vary depending on the gas composition nearby the electrode and thus peak positions can move around, leading to difficulty in species identification.

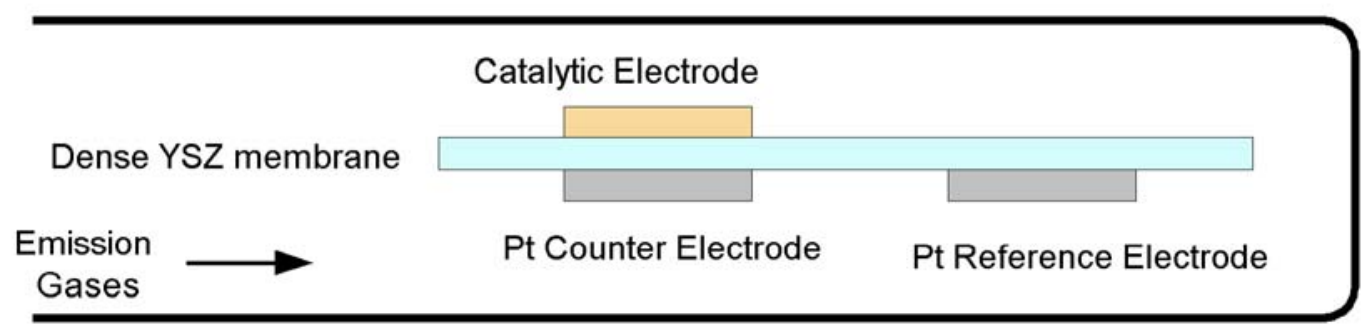

(1)

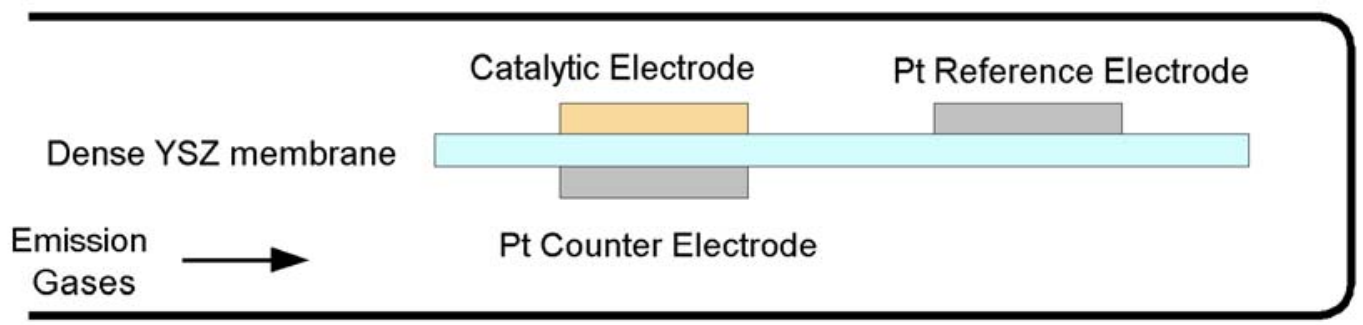

Figure 14. Two sensor designs (A1 and A2). In both designs, the catalytic electrode and auxiliary electrodes are in the emission gas stream. Only the placement of reference electrode is different. 
Figures 15 and 16 show the response of the sensor $\mathrm{A} 1$ with a $\mathrm{NiCr}_{2} \mathrm{O}_{4}$ catalytic electrode to $1000 \mathrm{ppm} \mathrm{NO}$, and $1000 \mathrm{ppm} \mathrm{NO}_{2}$ in $1 \% \mathrm{O}_{2}(10,000 \mathrm{ppm})$ at $700^{\circ} \mathrm{C}$, respectively. Although the peaks were broader than expected and the sensitivity was low, the results clearly demonstrated the applicability of pulse voltammetric techniques for the detection of emission gases. The peaks' broadening and low sensitivity can be ascribed to high diffusion coefficient and low activation energy of electroactive species in the gas phase at $700^{\circ} \mathrm{C}$. Because of the high diffusion rate, it was difficult to establish mass transfer control during the potential scan. The sensitivity and the resolution can be increased by better electrode design and better electrode fabrication. However, uncertainty about the reference electrode potential in this design made it difficult to establish peak positions, and thus we decided to continue further work with sensor designs that had a Pt/air reference electrode.

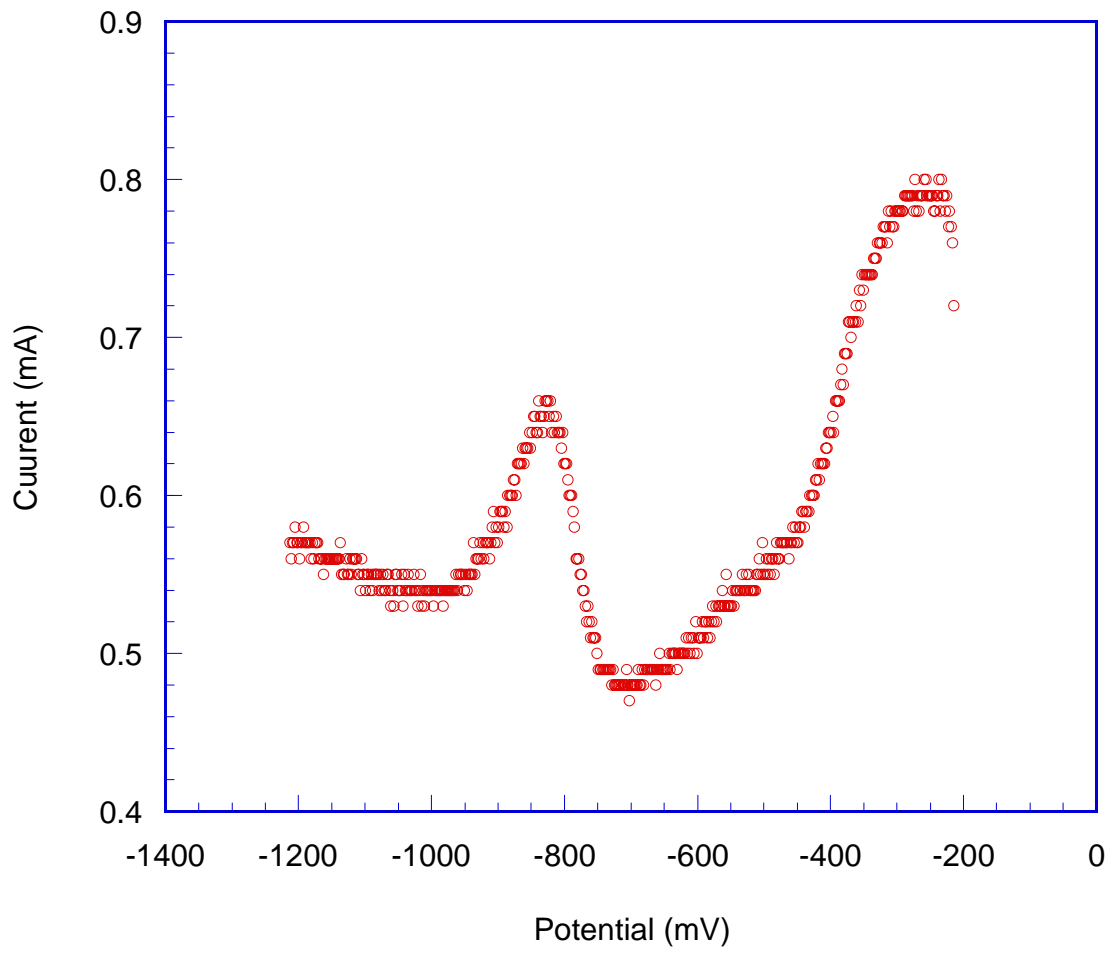

Figure 15. Square wave voltammogram for $\mathrm{NO}$ at $700^{\circ} \mathrm{C}$ on $\mathrm{NiCr}_{2} \mathrm{O}_{4}$ electrodes. 


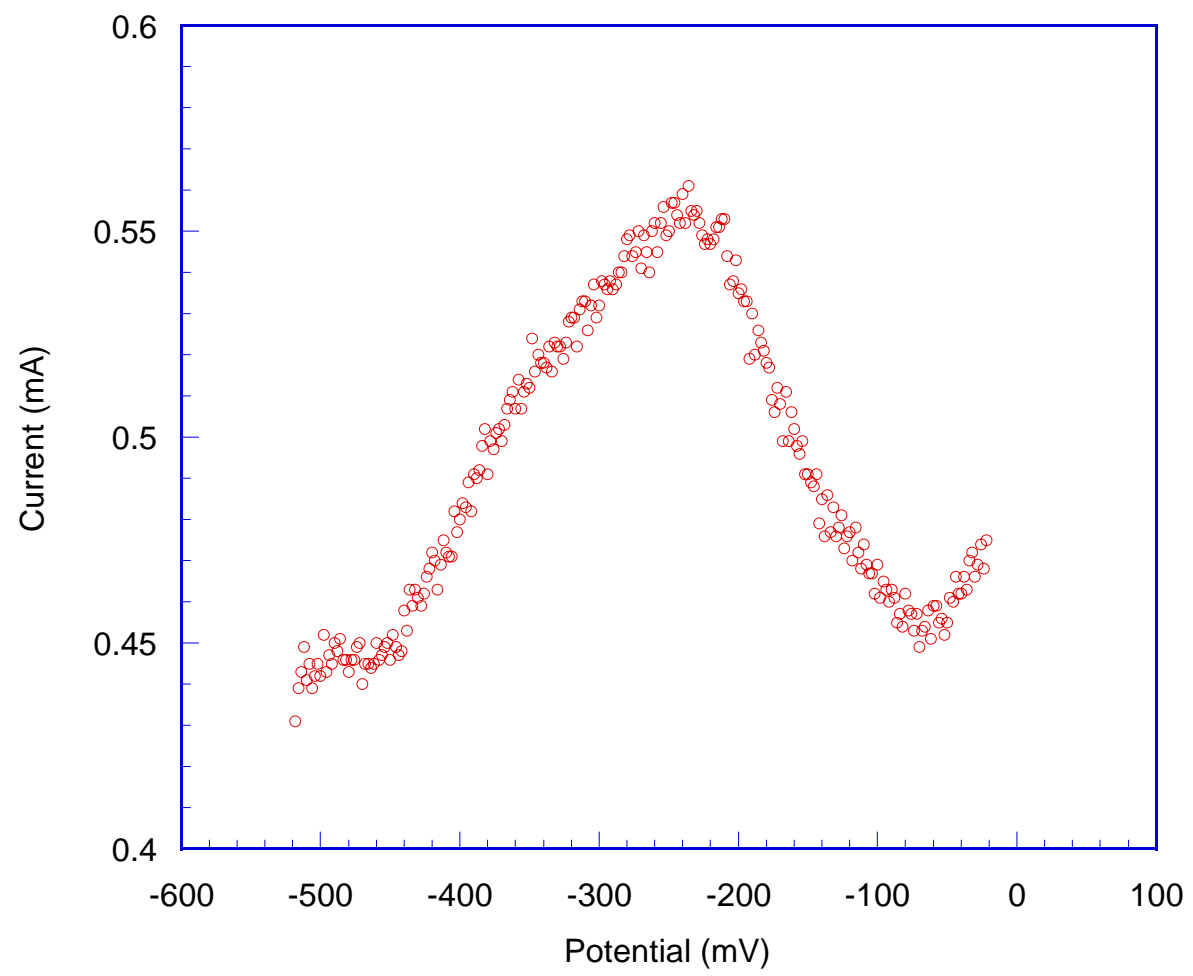

Figure 16. Square wave voltammogram for $\mathrm{NO}_{2}$ at $700^{\circ} \mathrm{C}$ on $\mathrm{NiCr}_{2} \mathrm{O}_{4}$ electrodes.

The sensor design shown in Figure 17 has both working and counter electrodes in the emission gas side, but the reference electrode is placed outside in ambient air. The electrode chambers were formed by sealing the cell to the alumina tube housing. Because the reference electrode is in equilibrium with the ambient air, its potential is determined by the Nernst potential according to the concentration of oxygen in the atmosphere. The placement of the electrode is also reasonably good in this design as it measures an equipotential surface between the two active surfaces. However, the cell current flows laterally through the membrane, and thus the cell resistance is significantly higher than in the previous design. This increased resistance poses a problem in pulse voltammetric techniques where high double layer charging and faradaic currents need to flow through the cell during pulsing. At lower temperatures $\left(\sim 600^{\circ} \mathrm{C}\right)$ where the response of species to the catalytic electrodes is at its best, the electronics became unstable because of the cell's high impedance. Therefore, we determined that this design was not suitable for pulse voltammetric techniques in which a significant amount of current is passed during the measurements. However, in potentiometric measurements, this sensor design would work well because no appreciable current is passed through the cell.

Figure 18 shows sensor design C, the design we studied the most intensively in Phase I. In this design, only the catalytic electrode is in the emission gas stream. Both the reference and counter electrodes are placed outside in ambient air, and thus the reference electrode potential is fixed by the oxygen in air similar to the previous design. Similar to design B, in cell design C the electrolyte is sealed to the cell housing (alumina tube), separating anodic and cathodic chambers. 


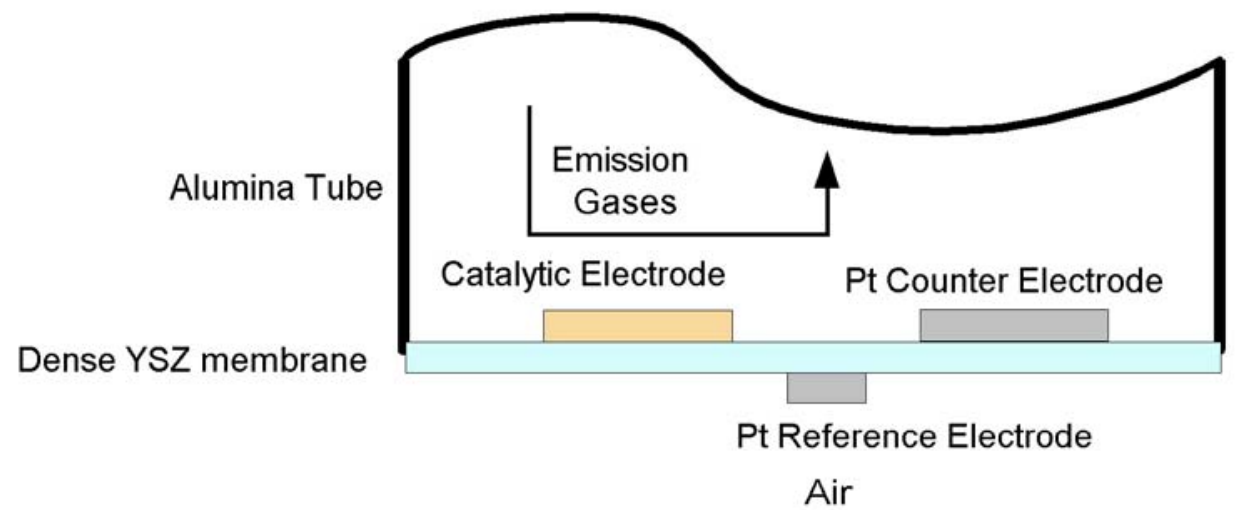

Figure 17. Sensor design (B) with a Pt/air reference electrode. The catalytic electrode and the counter electrode are in the emission gas stream.

The cell resistance of design C is relatively small because the electrolyte is thin (50-200 $\mu \mathrm{m})$, and thus we were able to perform voltammetric potential scans in this cell without making it electronically unstable. For low-temperature measurements $\left(500^{\circ} \mathrm{C}\right)$, the cell was further stabilized by capacitively coupling the reference and counter electrodes. We used the smallest capacitor that provided the stable cell circuit without compromising the response speed. The typical capacitors were in the 0.001 to $0.1 \mu \mathrm{F}$ range.

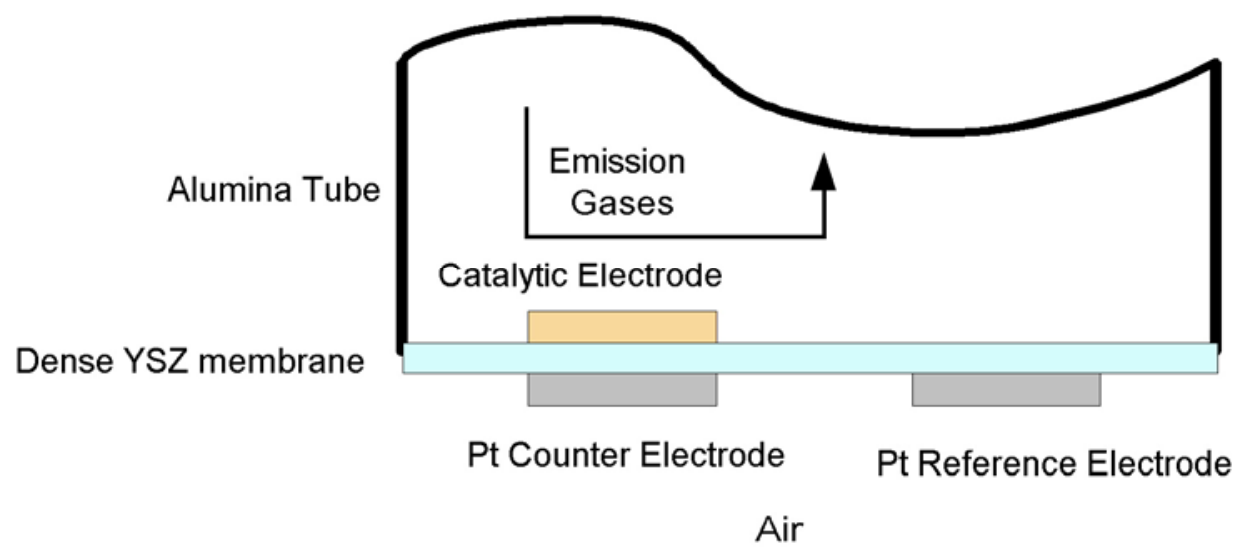

Figure 18. Sensor design (C) with a Pt/air reference electrode. The catalytic electrode is in the emission gas stream. The counter electrode and the reference electrode are in the air-side.

Figure 19 shows the response of sensor design $\mathrm{C}$ with a $\mathrm{CdMn}_{2} \mathrm{O}_{4}$ electrode to $\mathrm{NO}$ in $2 \% \mathrm{O}_{2}$ at $700^{\circ} \mathrm{C}$. The differential current peak was broad and the background current was high, indicating fast mass transfer at the electrode. It was difficult to obtain accurate calibration curves for low concentrations with this cell design. To improve the cell response in pulse voltammetric measurements, it is critical to establish mass transfer control of the electrochemical reaction. We used porous YSZ membranes to control the gas diffusion to the sensing electrode. 


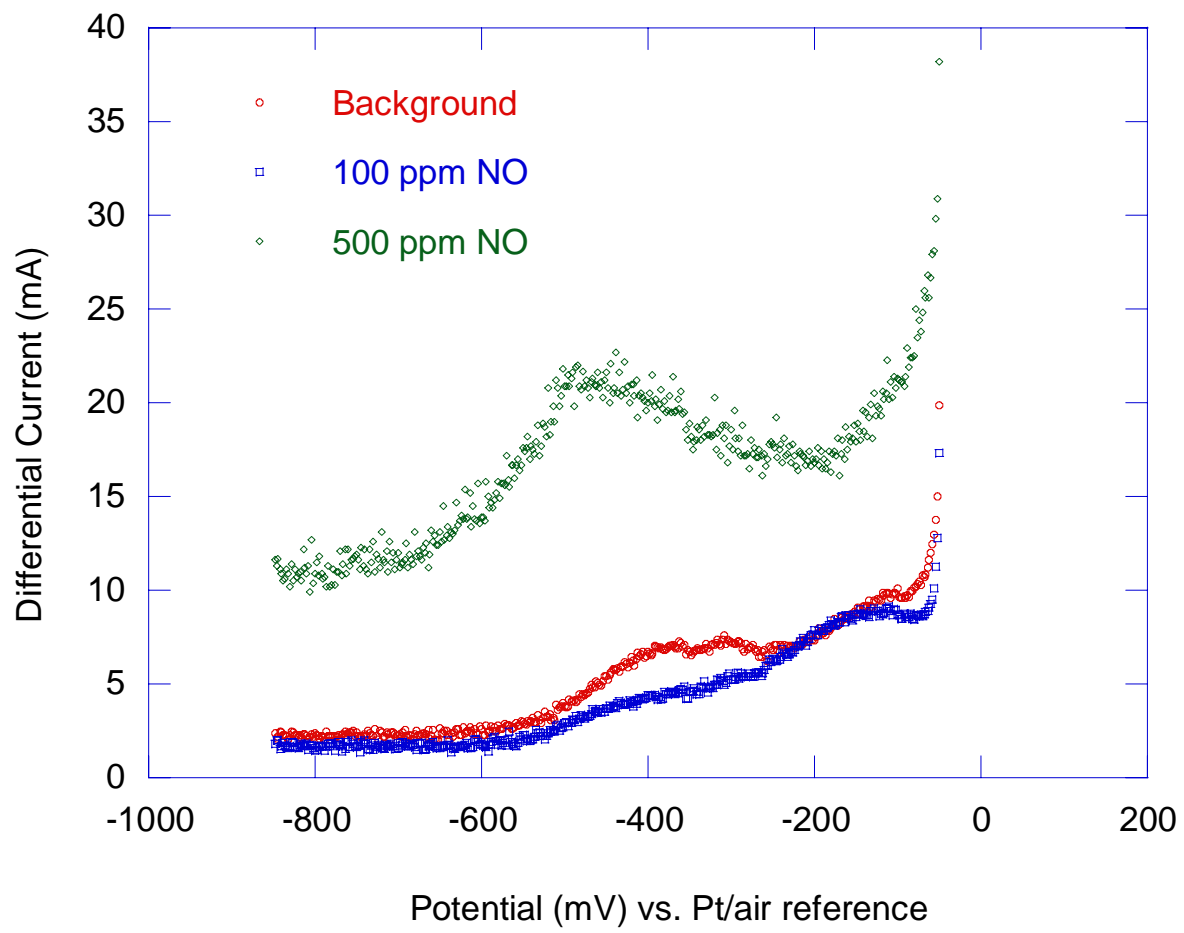

Figure 19. $\mathrm{CdMn}_{2} \mathrm{O}_{4}$ sensor response to $\mathrm{NO}$ in $2 \% \mathrm{O}_{2}$ at $700^{\circ} \mathrm{C}$

Sensor design D shown in Figure 20 is a modification of design C, with gas flow to the catalytic electrode restricted with a porous YSZ membrane. Sensor D was fabricated by attaching the porous YSZ to the sensor $\mathrm{C}$ with Aremco cement. Restricting the diffusion of gases to the electrode improved the performance of the sensor significantly. Figure 21 shows the response of the $\mathrm{NiCr}_{2} \mathrm{O}_{4}$ electrode to $\mathrm{NO}_{2}$ in $2 \% \mathrm{O}_{2}$ at $700^{\circ} \mathrm{C}$. The sensor response is clearly improved over that of design $\mathrm{C}$, and thus the detection limit significantly improved as well. The peak appeared at $0.4 \mathrm{~V}$, indicating that the peak corresponds to the second stage electron transfer reaction of $\mathrm{NO}_{2}$ reduction to $\mathrm{N}_{2}$. The first stage electron transfer $\left(\mathrm{NO}_{2}\right.$ to $\left.\mathrm{NO}\right)$ is apparently buried with the oxygen reduction around $0.0 \mathrm{~V}$, given that the selectivity is low at high temperatures.

To further optimize the sensor response, we decided to use a highly restricted flow design. Sensor design E shown in Figure 22 is another modification of C, with gas diffusion to the catalytic electrode severely restricted with a porous/dense YSZ membrane. The gases are allowed to reach the catalytic electrode through the small pinhole and the porous layer. Sensor E is fabricated by attaching the porous/dense YSZ to sensor C with Aremco cement, and then piercing a fine hole in the top dense layer with a microdrill. By restricting the diffusion of gases to the electrode, we significantly improved the sensitivity and the selectivity of the sensor.

Figure 23 shows the response of sensor $\mathrm{E}$ with a $\mathrm{CdMn}_{2} \mathrm{O}_{4}$ electrode to $\mathrm{NO}_{2}$ in $5 \% \mathrm{O}_{2}$ at $500^{\circ} \mathrm{C}$. The high background current is due to oxygen in the gas stream. Clearly, the electrode responded well to the changes in the concentration of $\mathrm{NO}_{2}$. The noise level in the current signals is somewhat higher than that at high temperature due to high cell resistance at low operating temperature $\left(500^{\circ} \mathrm{C}\right)$. The signal-to-noise ratio can be significantly improved by signal 
averaging of potential scans. Figure 24 shows the calibration curve obtained from the plots in Figure 23, indicating excellent linearity of the sensor response in the tested NO concentration range.

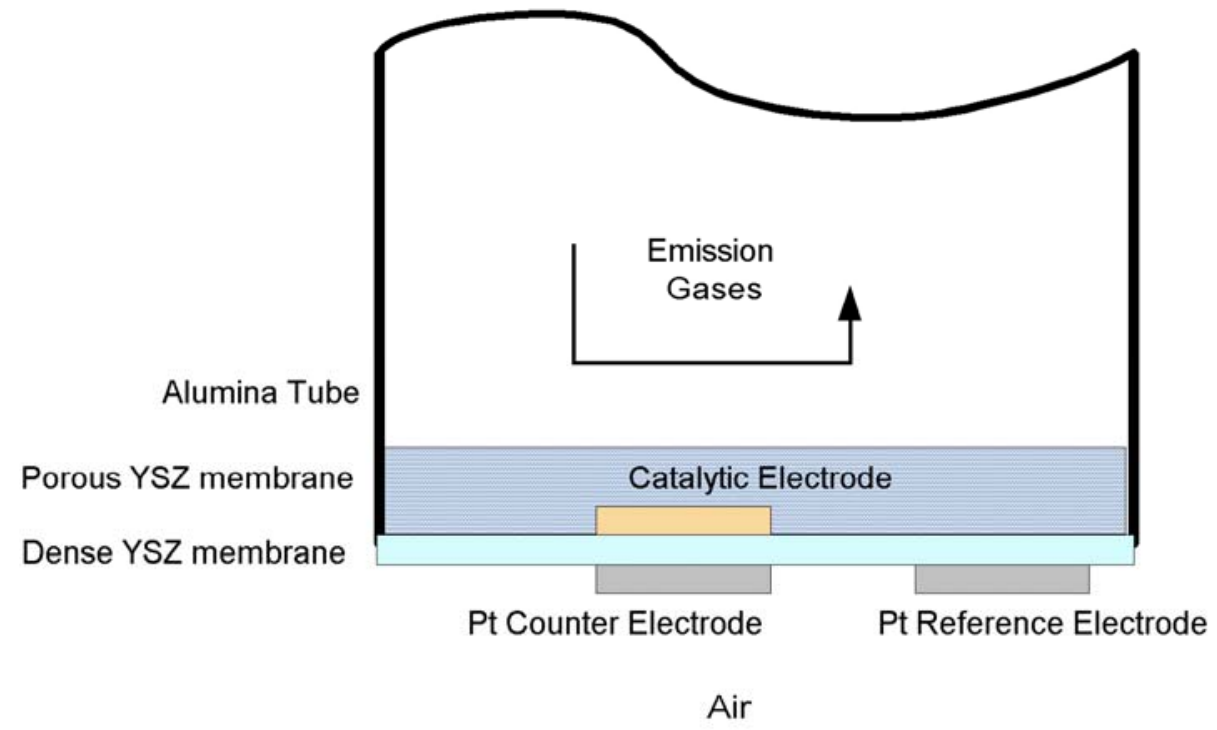

Figure 20. Sensor design (D) with a Pt/air reference electrode. The catalytic electrode is underneath a porous YSZ membrane in the emission gas chamber. The counter and the reference electrodes are in the air side.

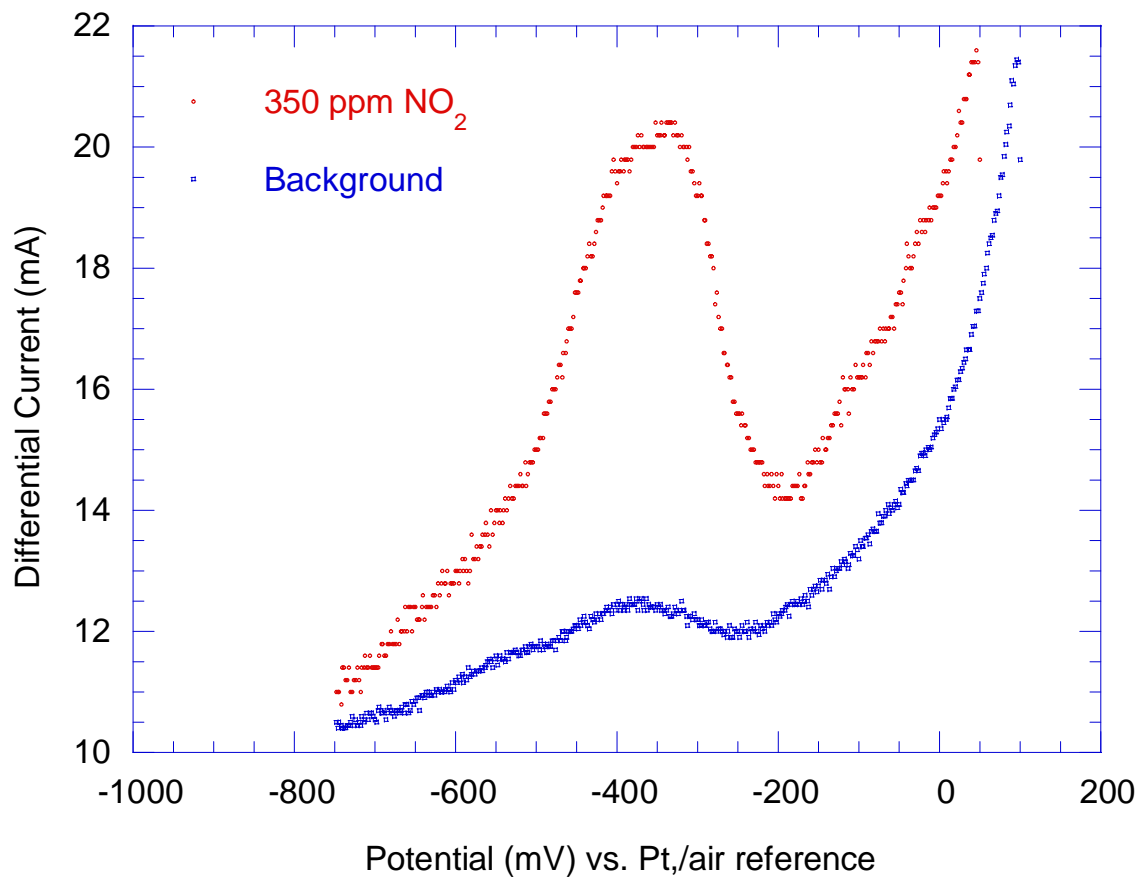

Figure 21 . $\mathrm{NiCr}_{2} \mathrm{O}_{4}$ sensor (D) response to $\mathrm{NO}$ in $2 \% \mathrm{O}_{2}$ at $700^{\circ} \mathrm{C}$. 


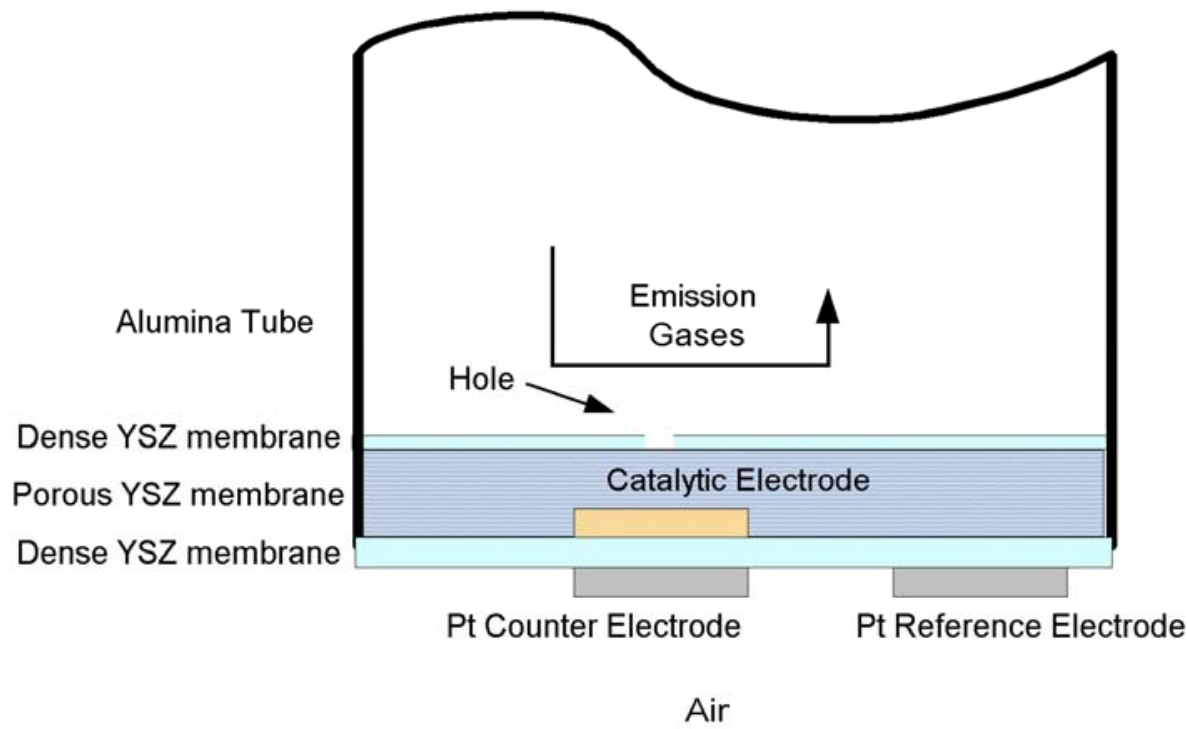

Figure 22. Sensor design (E) with a Pt/air reference electrode. The catalytic electrode is underneath a porous-dense YSZ membrane in the emission gas chamber. The counter and the reference electrodes are in the air side.

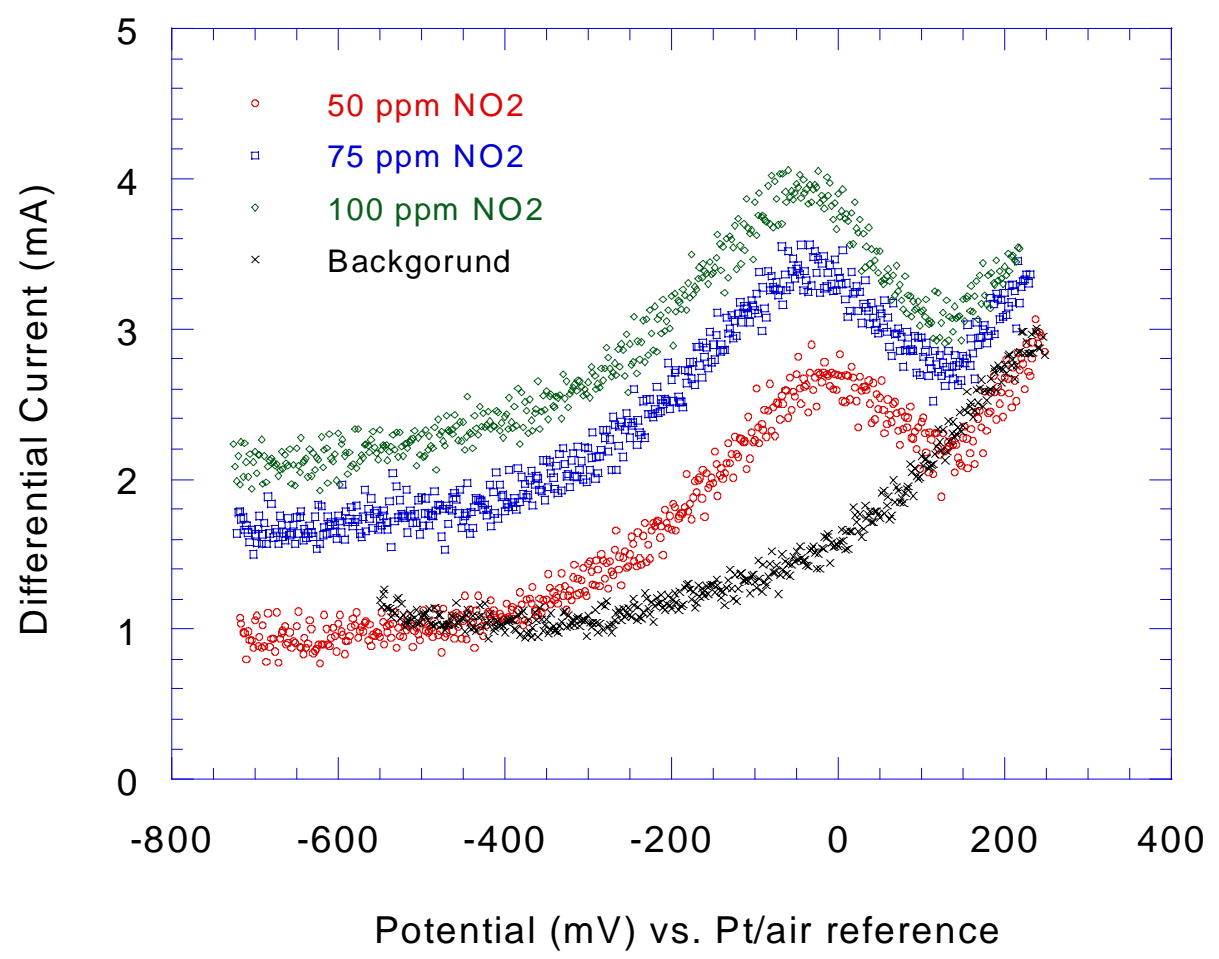

Figure 23. Response of sensor design $\mathrm{E}$ with $\mathrm{CdMn}_{2} \mathrm{O}_{4}$ to $\mathrm{NO}_{2}$ in $5 \% \mathrm{O}_{2}$ at $500^{\circ} \mathrm{C}$ 


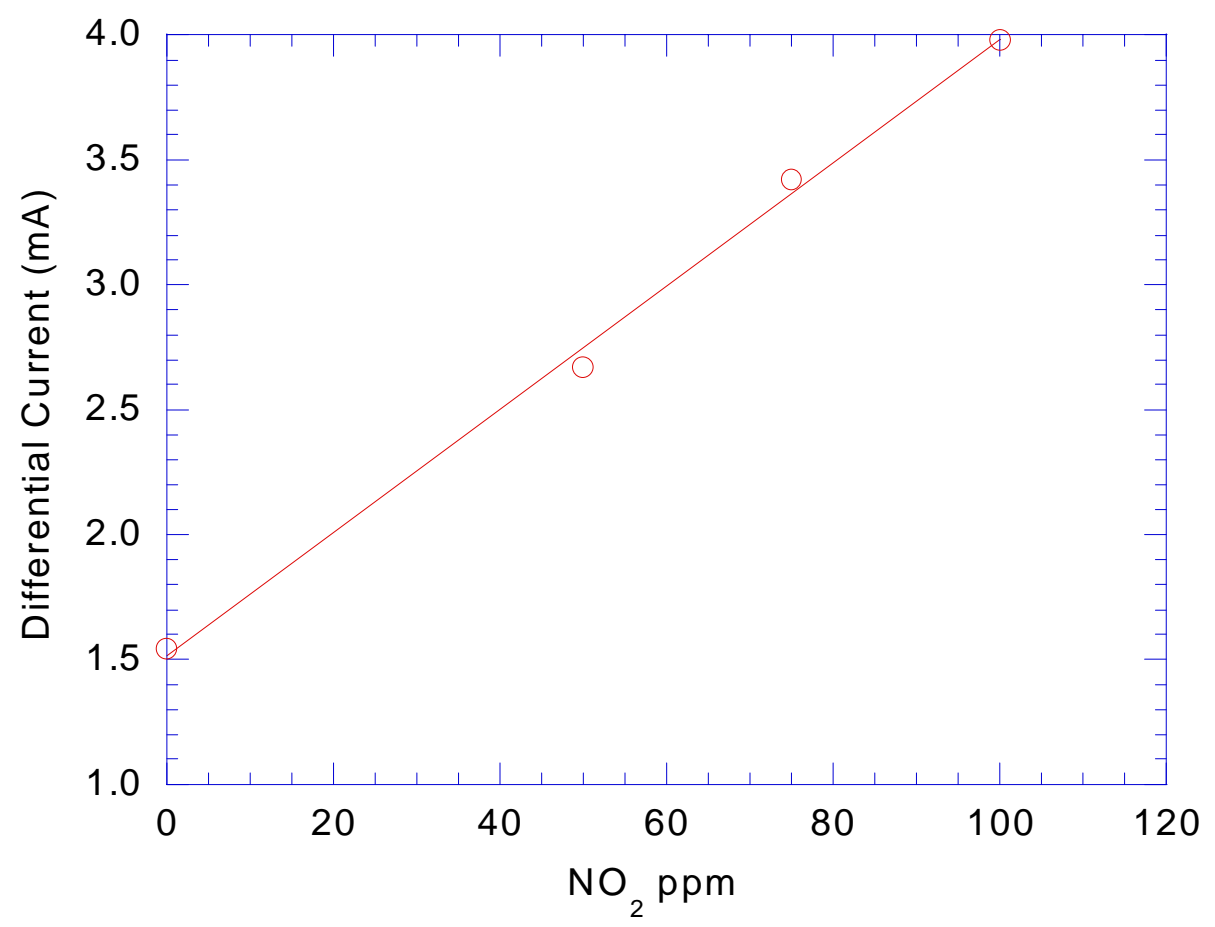

Figure 24. Calibration plot of sensor $\mathrm{E}$ with $\mathrm{CdMn}_{2} \mathrm{O}_{4}$ for $\mathrm{NO}_{2}$ in $5 \% \mathrm{O}_{2}$ at $500^{\circ} \mathrm{C}$.

Figure 25 shows the response of sensor $\mathrm{E}$ with a $\mathrm{CdMn}_{2} \mathrm{O}_{4}$ electrode to $\mathrm{NO}_{2}$ in $2 \% \mathrm{O}_{2}$ at $700^{\circ} \mathrm{C}$. The peak position is shifted because the concentration of oxygen in the gas stream and the temperature is different from the previous experiment. Nevertheless, the electrode responded well to the changes in the concentration of $\mathrm{NO}_{2}$. The noise level in the response signal was lower at high temperature because the resistance is low in the electrochemical cell. Figure 26 shows the calibration curve obtained from these plots, which indicates excellent linearity in the tested $\mathrm{NO}_{2}$ concentration range.

Figure 27 shows the response of sensor $\mathrm{E}$ with an LSF electrode to $\mathrm{NO}$ and $\mathrm{CO}$ in $2 \% \mathrm{O}_{2}$ at $700^{\circ} \mathrm{C}$. The peak at $50 \mathrm{mV}$ corresponds to $\mathrm{CO}$ and that at $-250 \mathrm{mV}$ corresponds to NO. The peaks in the voltammogram are well resolved, and thus species can be readily identified from their peak potentials. This experiment clearly demonstrates that the use of pulse voltammetric techniques for multicomponent detection is feasible on a single electrode. The calibration curve obtained from these plots in Figure 28 indicates excellent linearity in the tested $\mathrm{NO}$ and $\mathrm{CO}$ concentration ranges. 


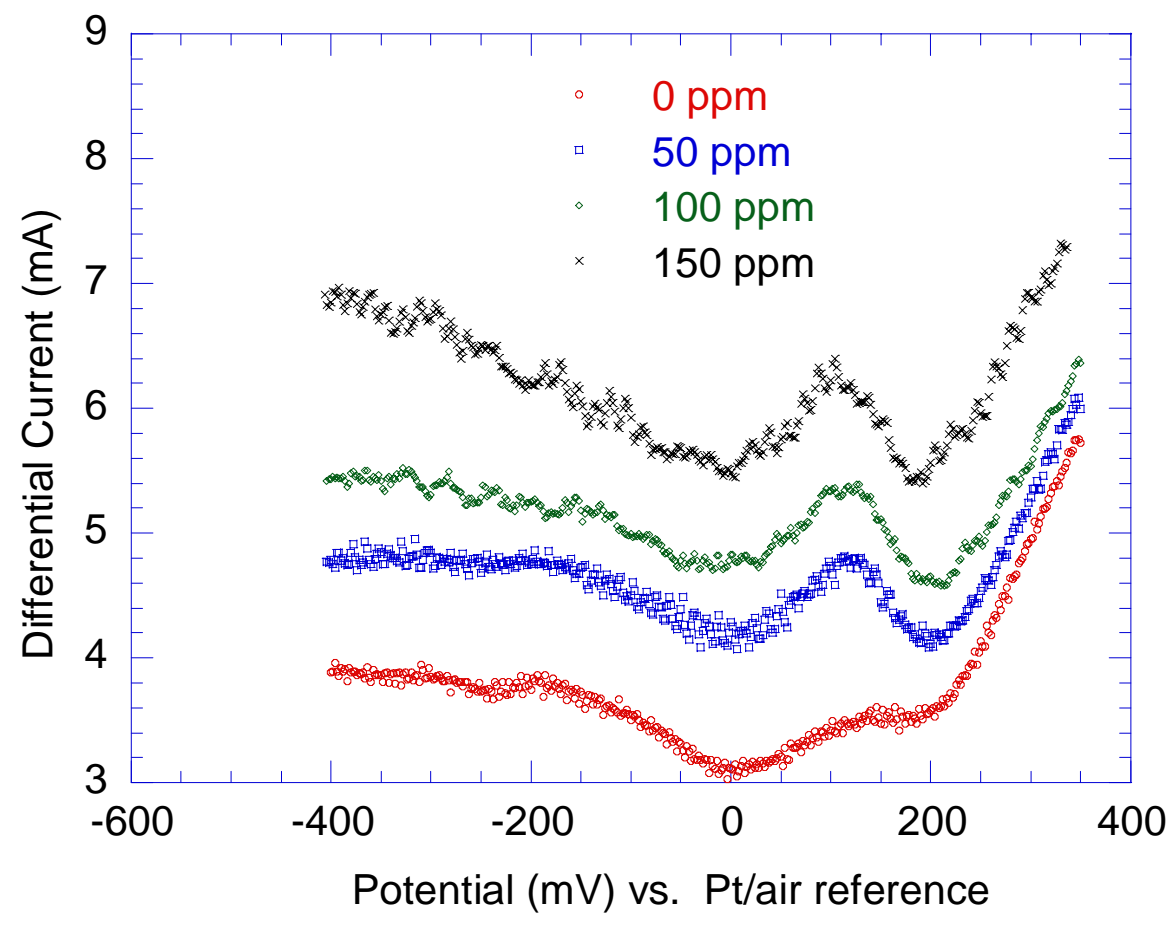

Figure 25. Response of sensor design $\mathrm{E}$ with $\mathrm{CdMn}_{2} \mathrm{O}_{4}$ to $\mathrm{NO}_{2}$ in $2 \% \mathrm{O}_{2}$ at $700^{\circ} \mathrm{C}$.

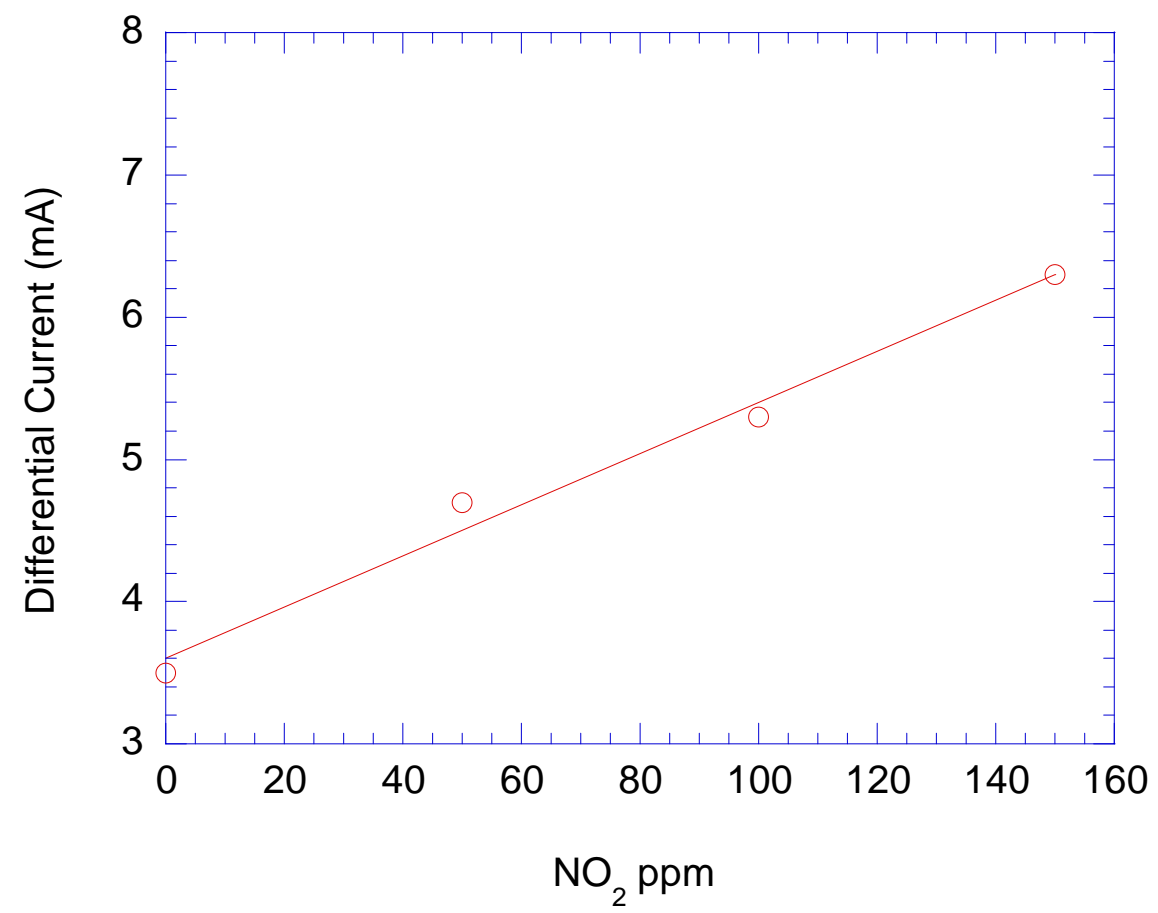

Figure 26. Calibration plot of sensor design $\mathrm{E}$ with $\mathrm{CdMn}_{2} \mathrm{O}_{4}$ for $\mathrm{NO}_{2}$ in $2 \% \mathrm{O}_{2}$ at $700^{\circ} \mathrm{C}$. 


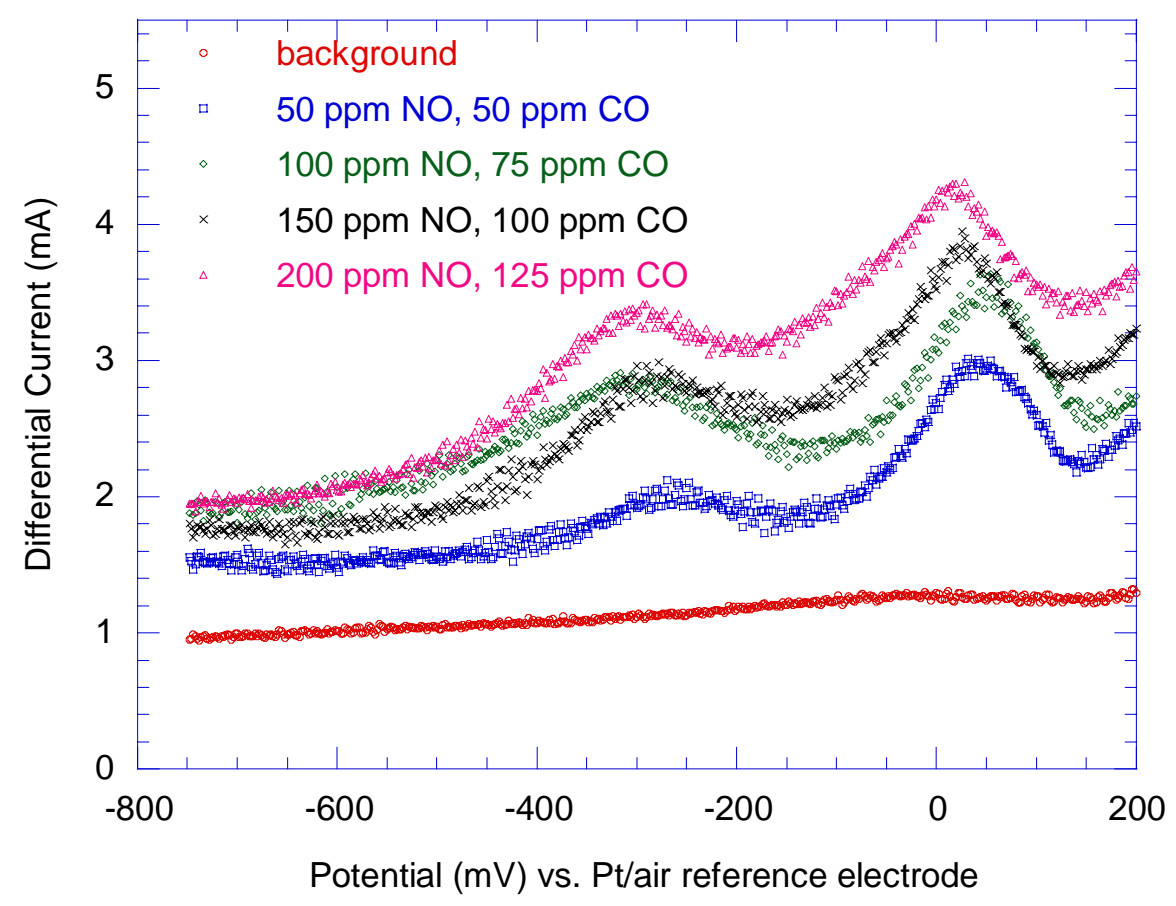

Figure 27. Response of sensor design $\mathrm{E}$ with an $\mathrm{LSF}$ electrode to $\mathrm{NO}$ and $\mathrm{CO}$ in $2 \% \mathrm{O}_{2}$ at $700^{\circ} \mathrm{C}$.

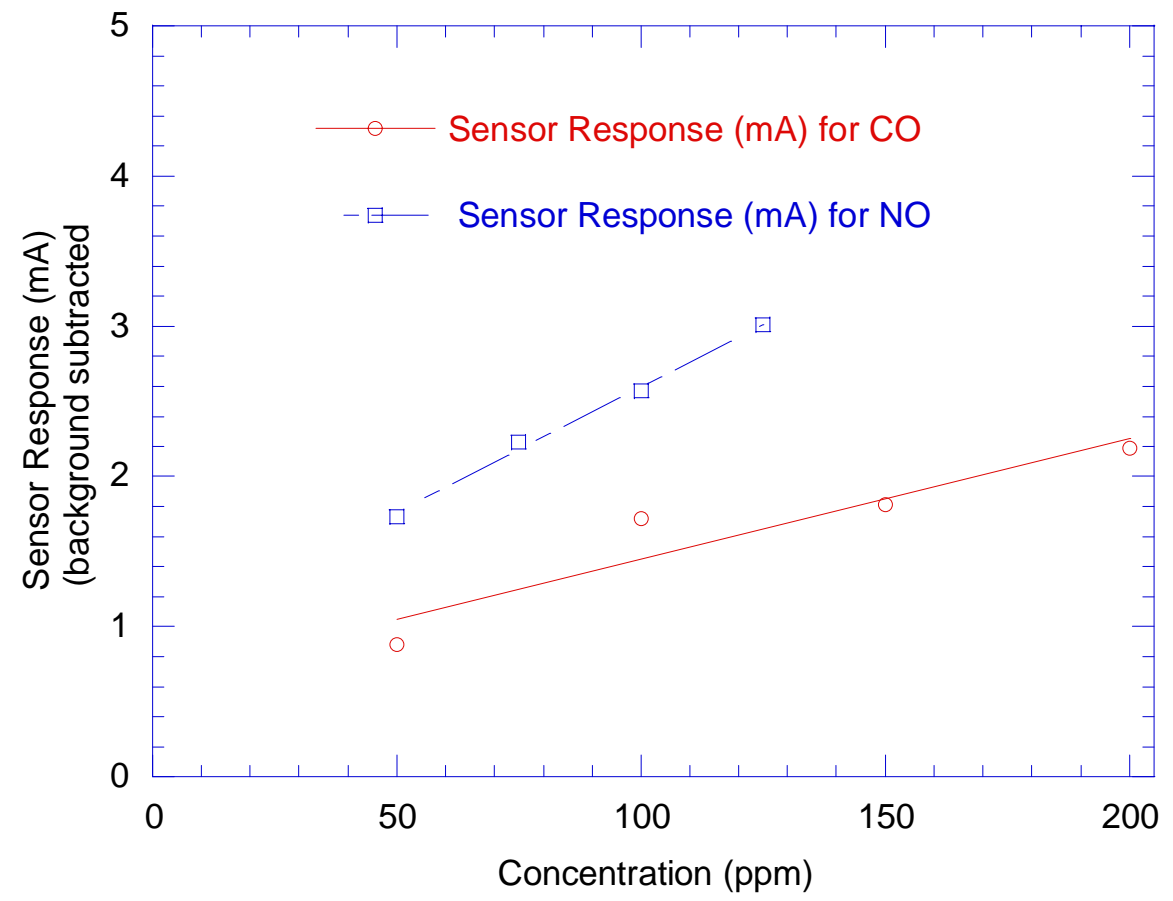

Figure 28. Calibration plot of sensor design $\mathrm{E}$ with an LSF electrode for $\mathrm{NO}$ and $\mathrm{CO}$ in $2 \% \mathrm{O}_{2}$ at $700^{\circ} \mathrm{C}$. 


\section{AC Impedance Analysis}

The AC impedance analysis of the sensor provides a wealth of information such as frequency response, electrode kinetics, ionic and electronic conductivities, and capacitance of the electrochemical interface. Figure 29 shows AC impedance Nyquist plots for sensor design E with a $\mathrm{CdMn}_{2} \mathrm{O}_{4}$ in $2 \% \mathrm{O}_{2}$ at $600^{\circ} \mathrm{C}$ with and without $100 \mathrm{ppm} \mathrm{NO}_{2}$. The Bode plots (impedance, phase vs. frequency) of the same data are presented in Figures 30 and 31.

In the complex plane Nyquist plots, it is evident that the polarization resistance of the electrode decreases with introduction of $\mathrm{NO}_{2}$. The decrease stems from the low frequency response of the electrode, indicating that the mass transfer rate of the electrochemical reaction is affected by the presence of $\mathrm{NO}_{2}$. We believe that $\mathrm{NO}_{2}$ is preferentially adsorbed in the porous catalytic electrode and thus is more readily available than oxygen to migrate to an active site for reduction. The phase angles in two frequency scans shown in Figure 31 indicate that reduction in interfacial capacitance in the 10 to $1000 \mathrm{~Hz}$ frequency range. This effect is most likely due to a combination of slight differences in charge transfer and diffusion of two active species.

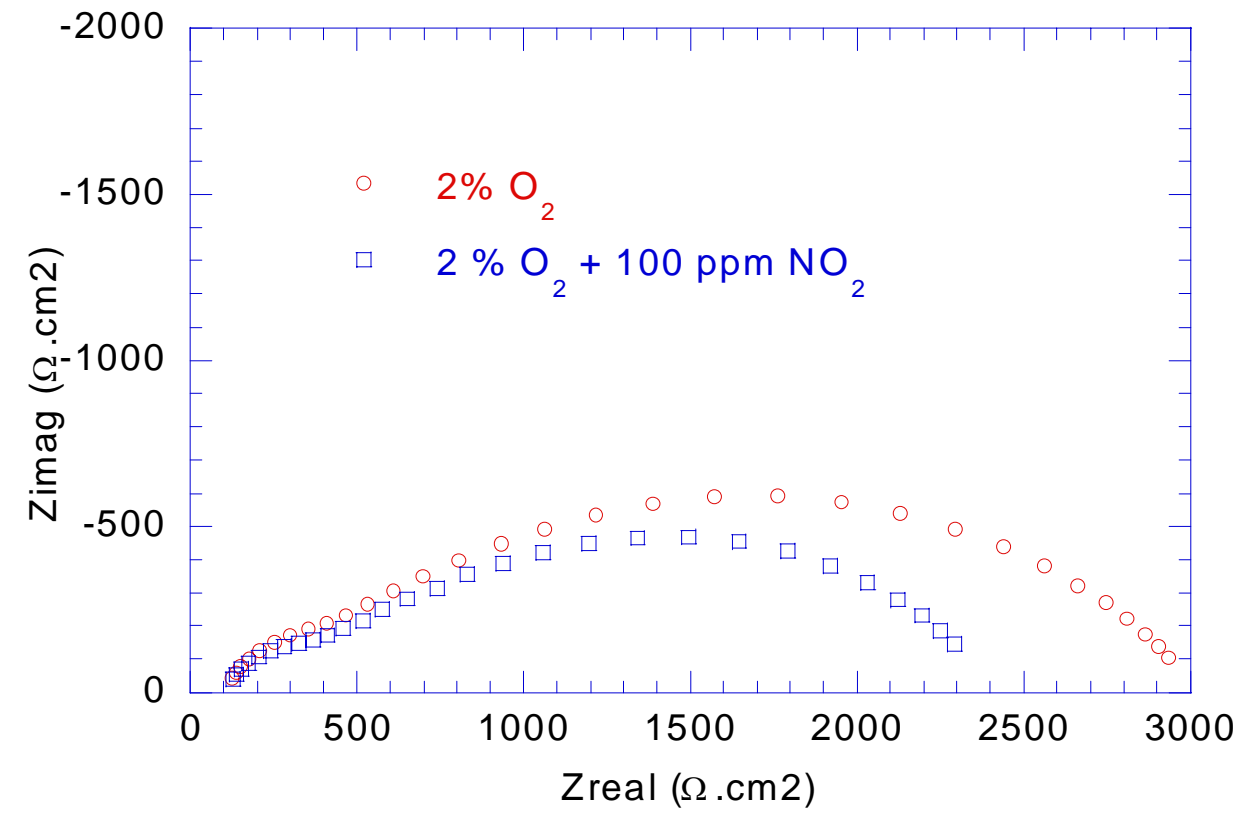

Figure 29. Nyquist plots for sensor design $\mathrm{E}$ with $\mathrm{CdMn}_{2} \mathrm{O}_{4}$ in $2 \% \mathrm{O}_{2}$ at $600^{\circ} \mathrm{C}$ with and without 100 ppm $\mathrm{NO}_{2}$. 


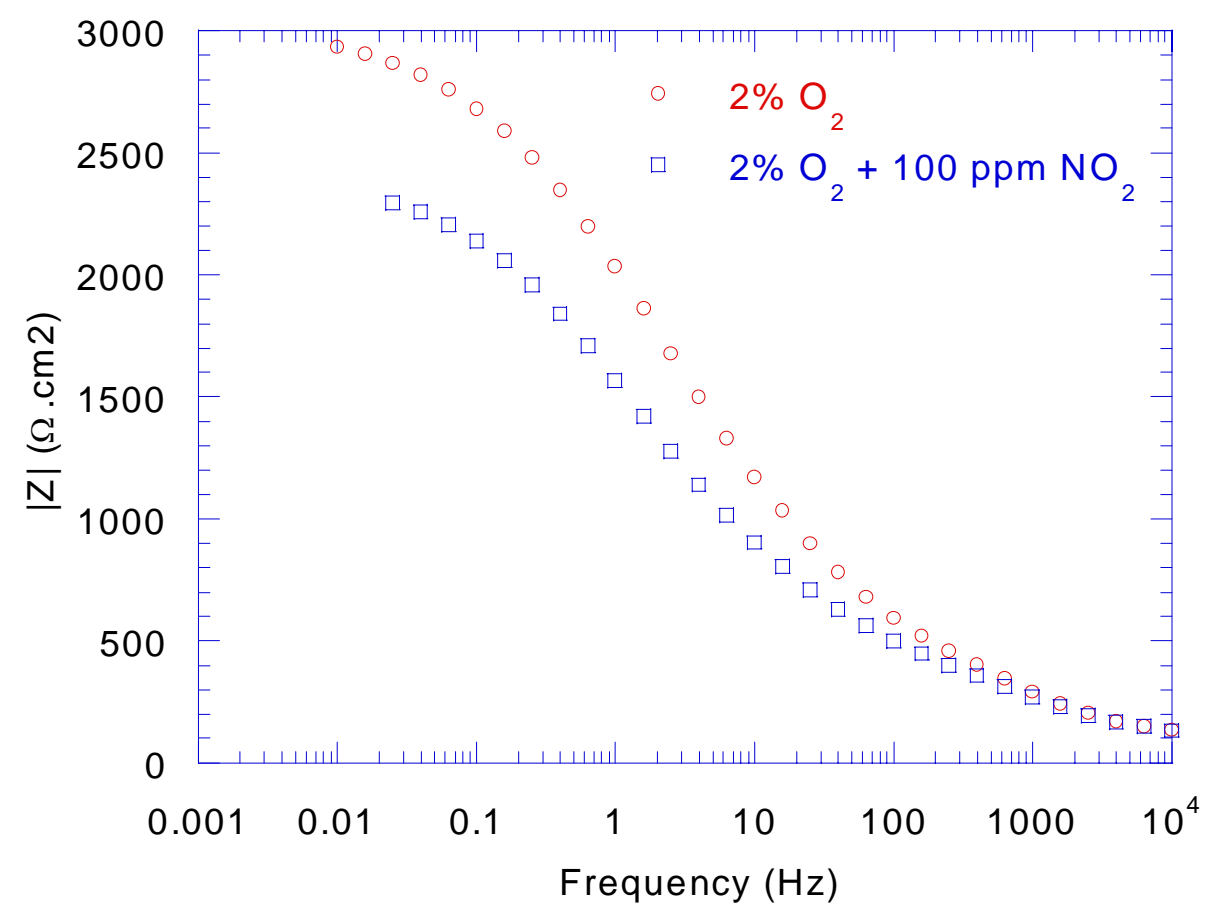

Figure 30. Bode plots (impedance-frequency) for sensor design $\mathrm{E}$ with $\mathrm{CdMn}_{2} \mathrm{O}_{4}$ in $2 \% \mathrm{O}_{2}$ at $600^{\circ} \mathrm{C}$ with and without $100 \mathrm{ppm} \mathrm{NO}_{2}$.

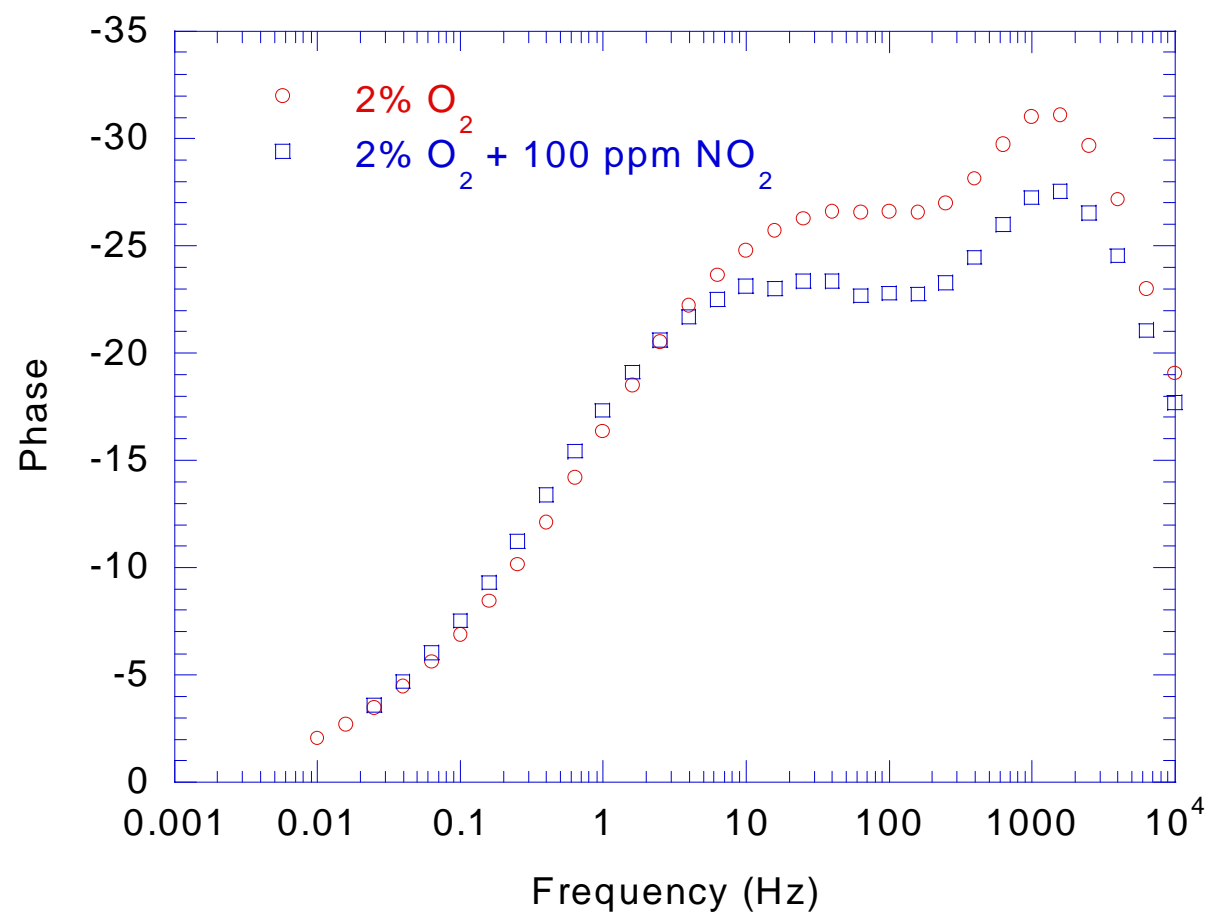

Figure 31. Bode plots (phase-frequency) for sensor design $\mathrm{E}$ with $\mathrm{CdMn}_{2} \mathrm{O}_{4}$ in $2 \% \mathrm{O}_{2}$ at $600^{\circ} \mathrm{C}$ with and without $100 \mathrm{ppm} \mathrm{NO}_{2}$. 


\section{Proposed Sensor Mechanism}

The electrochemical reactions occurring at the three-phase boundary of the solid electrolyte, electrode, and the gas phase can be expressed as follows.

\section{Reduction:}

$$
\begin{aligned}
& \mathrm{NO}_{2}+2 e \leftrightarrow \mathrm{O}^{2-}+\mathrm{NO} \\
& \mathrm{O}_{2}+4 e \leftrightarrow 2 \mathrm{O}^{2-} \\
& 2 \mathrm{NO}+4 e \leftrightarrow \mathrm{N}_{2}+2 \mathrm{O}^{2-}
\end{aligned}
$$

Oxidation:

$$
\begin{aligned}
& \mathrm{CO}+\mathrm{O}^{2-} \leftrightarrow \mathrm{CO}_{2}+2 e \\
& \mathrm{NO}+\mathrm{O}^{2-} \leftrightarrow \mathrm{NO}_{2}+2 e \\
& 2 \mathrm{O}^{2-} \leftrightarrow \mathrm{O}_{2}+2 e
\end{aligned}
$$

These reactions give rise to the mixed potential at the sensor electrode in the emission gas phase. By proper selection of catalytic material, a specific reaction can be forced to occur preferentially at the sensor electrode. The number of oxygen ions accumulated at the interface can be strongly influenced by the electrode material, its surface morphology, and its catalytic activity. The porous layer and chemical properties of semiconducting oxide enhance the adsorption of gas molecules and hence promote reduction or oxidation of reactions of $\mathrm{NO}, \mathrm{NO}_{2}$, or $\mathrm{CO}$ over that of $\mathrm{O}_{2}$. Therefore, under some polarization, the cell current changes with the exposure of the electrolyte/oxide interface to the pollutant gases. However, sensitivity of the sensor is quite low in a large excess of oxygen, which always competes at the electrode. Hence, the mixed potential theory reasonably explains the low sensitivity in both potentiometric and amperometric measurements.

In the pulse voltammetric measurements, the electrode interface is perturbed and thus larger transient signals are generated, thereby improving the sensitivity of the electrode. To obtain the maximum benefit of this technique, the gas diffusion to the electrode must also be restricted because the charge transfer rate at the electrode is comparable with the gas phase mass transfer rate at high temperature. We observed significant improvement of the sensor response in sensor designs with a porous YSZ layer on the catalytic electrode that restricted the mass transfer to the electrode surface.

\section{Temperature and Oxygen Concentration Limits}

The catalytic advantage of the materials used in the current sensor designs begins to fade above $800^{\circ} \mathrm{C}$ resulting in loss of selectivity between oxygen and analytes. At these temperatures, the current increased linearly with voltage due to the reduction of $\mathrm{O}_{2}$ and thus, disappearing the peaks in the differential voltammogram. The operational temperature may be raised above $800^{\circ} \mathrm{C}$ with different catalytic materials that have selectivity at higher temperatures.

The upper limit of the oxygen concentration was about $10 \%$ where the sensor was saturated and stopped responding to changes in the concentration of the analyte. To operate sensors above $10 \% \mathrm{O}_{2}$, the oxygen must be removed by auxiliary electrodes as shown in the conceptual design 
in Figure 1. If the prototype sensors are to be used in a high $\mathrm{O}_{2}$ environment, we will be able to incorporate the auxiliary electrodes into the final design.

\section{Other Combustion Gas Monitoring Technologies}

Other popular gas sensing technologies mainly include optical methods, where the chromophore of the pollutant species is measured to detect and quantify the species. Among these techniques, tunable diode laser sensing in combustion environments has attracted attention for detection of trace species such as $\mathrm{CO}, \mathrm{NO}$ and $\mathrm{CO}_{2}$. Although these sensor work well at low temperatures, high temperature in situ detection has been a major challenge. In the near-IR overtone region between 1.31 and $1.65 \mu \mathrm{m}$, high temperature measurements of ppm levels of pollutants are complicated by interferences from poorly understood high temperature transitions of water vapor, a major combustion species. Thus, fast extractive sampling combined with gas cooling and drying has been used to demonstrate the optical technique for pollutant concentration measurements. These requirements, other instrumentations needs, and the cost are major impediments for the widespread use of these optical techniques. 


\section{CONCLUSIONS}

We have completed preliminary selection of materials for catalytic electrodes to detect NO, $\mathrm{NO}_{2}$, and $\mathrm{CO}$ in emission gas environment using pulse voltammetry in a solid-state electrochemical cell. For the electrolyte, we used thin YSZ membranes that were fabricated by tape casting and sintering, with the electrodes painted on the electrolyte using slurries of the catalytic materials. We optimized the sintering profiles to obtain pinhole-free thin YSZ electrolytes and to attach the catalytic electrode. The typical thickness of the electrolyte is about 50 to $200 \mu \mathrm{m}$, and that of the electrodes is about 20 to $30 \mu \mathrm{m}$.

We have tested sensor electrodes made of three catalytic materials $-\mathrm{CdMn}_{2} \mathrm{O} 4, \mathrm{NiCr}_{2} \mathrm{O}_{4}$, and LSF - for their selectivity and sensitivity for emission gases. We fabricated a number of sensor designs and tested them for performance at temperatures from $500^{\circ}$ to $800^{\circ} \mathrm{C}$ in a flowthrough cell. We varied the geometry, methods of electrode fabrication, and the potential scan parameters to optimize sensor performance.

We have developed software and interfaced a potentiostat with a computer for pulse waveform generation and data acquisition. We wrote the custom software for the sensor so that it could be easily incorporated into on-line exhaust monitoring systems. We confirmed the operation of the software using a known aqueous electrochemical cell containing $\mathrm{Cd}^{2+}$ and $\mathrm{Pb}^{2+}$.

We have successfully demonstrated that emission gases such as $\mathrm{NO}, \mathrm{NO}_{2}$, and $\mathrm{CO}$ can be detected in the presence of excess $\mathrm{O}_{2}$ in a solid-state electrochemical cell using pulse voltammetric techniques on a catalytic electrode. $\mathrm{NO}_{2}$ and $\mathrm{NO}$ can be detected on either $\mathrm{CdMn}_{2} \mathrm{O} 4$ or $\mathrm{NiCr}_{2} \mathrm{O}_{4}$ electrodes in a diffusion-restricted cell. $\mathrm{CO}$ and $\mathrm{NO}$ can be detected on an LSF electrode. Because the peak potentials are different, the species can be easily identified in the voltammogram. The calibration plots that we obtained for each of these gases on the respective electrodes show excellent linearity, indicating that the technique can be used reliably to monitor exhaust gas streams.

The solid-state electrochemical cell and the electrode design have been critical for obtaining sensitivity and selectivity. As the diffusion of gases to the catalytic electrode must be restricted to obtain mass transfer control in electrochemical reactions, a simple cell design with a catalytic electrode does not provide adequate sensitivity or selectivity for the detection of emission gases. Because the mass transfer rate is very high in the gas phase, the charge transfer rate would not be sufficient to establish a mass transfer controlled reaction and thus the cell current would not reach a plateau as in the case in typical aqueous solutions.

We have proposed a mechanism for selectivity of the species based on mixed potential at the electrochemical interface. From pulse electrochemical measurements and AC impedance analysis, we believe that the species are preferentially adsorbed on the catalyst-electrolyte interface, and thus change the response of the electrode to the voltage waveform. Depending on the bias of the electrode, the activities of the species adsorbed are different, and thus multiple species can be detected on a single electrode. 


\section{REFERENCES}

1. T. Gur and R.A. Huggins, J. Electrochem. Soc., 140 (1993) 1990.

2. M.W. Verbruggee and D.W. Dees, J. Electrochem. Soc., 140 (1993) 2001.

3. A. Sharma and P.D. Pacey, J. Electrochem. Soc., 140 (1993) 2302.

4. N. Yamazoe and N. Miura, Solid State Ionics, 86-88 (1996) 987.

5. N. Miura, M. Nakatou and S. Zhuiykov, Electrochem. Comm., 4 (2002) 284.

6. N. Miura, S. Zhuiykov, T. Ono, M. Hasei and N. Yamazoe, Sensors Actuators, B83 (2002) 222.

7. N. Li, T.C. Tan and H.C. Zeng, J. Electrochem. Soc., 140 (1993) 1068.

8. T. Hibino, S. Tanimoto, S. Kakimoto and M. Sano, Electrochem. Solid State Lett., 2 (1999) 651.

9. A. Hashimoto, T. Hibino, K. Mori and M. Sano, Sensors Actuators, B81 (2001) 55.

10. N. Miura, G. Lu and N. Yamazoe, Sensors Actuators, B52 (1998) 169.

11. G. Lu, N. Miura and N. Yamazoe, J. Appl. Electrochem., 28 (1998) 1009.

12. S. Somov, G. Reinhardt, U. Guth and W. Gopel, Sensors Actuators, B35-36 (1996) 409.

13. W. Gopel, G. Reinhardt and M. Rosch, Solid State Ionics, 136-137 (2000) 519.

14. S. Masia, P.D. Calvert, W.E. Rhine, and H.K. Brown, J. Mater. Sci., 24 (1999) 1907-1912. 